\title{
Spectral light absorption by ambient aerosols influenced by biomass burning in the Amazon Basin. I: Comparison and field calibration of absorption measurement techniques
}

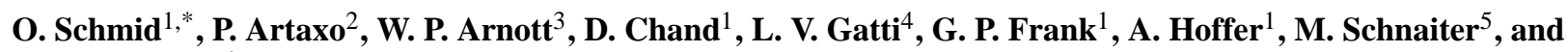 \\ M. O. Andreae ${ }^{1}$ \\ ${ }^{1}$ Max Planck Institute for Chemistry, Department of Biogeochemistry, P.O. Box 3060, 55020 Mainz, Germany \\ ${ }^{2}$ University of São Paulo, Institute of Physics, São Paulo, Brazil \\ ${ }^{3}$ Desert Research Institute, Division of Atmospheric Science, Reno, NV, USA \\ ${ }^{4}$ Institute of Nuclear Energy Research, Atmospheric Chemistry Laboratory, São Paulo, SP, Brazil \\ ${ }^{5}$ Research Center Karlsruhe, Institute of Meteorology and Climate Research, P.O. Box 3640, 76021 Karlsruhe, Germany \\ *now at: GSF-Research Center for Environment and Health, Institute for Inhalation Biology, P.O. Box 1129, 85758 \\ Neuherberg/Munich, Germany
}

Received: 11 July 2005 - Published in Atmos. Chem. Phys. Discuss.: 29 September 2005

Revised: 12 July 2006 - Accepted: 26 July 2006 - Published: 21 August 2006

\begin{abstract}
Spectral aerosol light absorption is an important parameter for the assessment of the radiation budget of the atmosphere. Although on-line measurement techniques for aerosol light absorption, such as the Aethalometer and the Particle Soot Absorption Photometer (PSAP), have been available for two decades, they are limited in accuracy and spectral resolution because of the need to deposit the aerosol on a filter substrate before measurement. Recently, a 7-wavelength $(\lambda)$ Aethalometer became commercially available, which covers the visible (VIS) to near-infrared (NIR) spectral range $(\lambda=450-950 \mathrm{~nm})$, and laboratory calibration studies improved the degree of confidence in these measurement techniques. However, the applicability of the laboratory calibration factors to ambient conditions has not been investigated thoroughly yet.

As part of the LBA-SMOCC (Large scale Biosphere atmosphere experiment in Amazonia - SMOke aerosols, Clouds, rainfall and Climate) campaign from September to November 2002 in the Amazon basin we performed an extensive field calibration of a $1-\lambda$ PSAP and a 7- $\lambda$ Aethalometer utilizing a photoacoustic spectrometer (PAS, $532 \mathrm{~nm}$ ) as reference device. Especially during the dry period of the campaign, the aerosol population was dominated by pyrogenic emissions. The most pronounced artifact of integrating-plate type attenuation techniques (e.g. Aethalometer, PSAP) is due to multiple scattering effects within the filter matrix. For
\end{abstract}

the PSAP, we essentially confirmed the laboratory calibration factor by Bond et al. (1999). On the other hand, for the Aethalometer we found a multiple scattering enhancement of 5.23 (or 4.55, if corrected for aerosol scattering), which is significantly larger than the factors previously reported $(\sim 2)$ for laboratory calibrations. While the exact reason for this discrepancy is unknown, the available data from the present and previous studies suggest aerosol mixing (internal versus external) as a likely cause. For Amazonian aerosol, we found no absorption enhancement due to hygroscopic particle growth in the relative humidity $(R H)$ range between $40 \%$ and $80 \%$. However, a substantial bias in PSAP sensitivity that correlated with both $R H$ and temperature (T) was observed for $20 \%<R H<30 \%$ and $24^{\circ} \mathrm{C}<\mathrm{T}<26^{\circ} \mathrm{C}$, respectively. In addition, both PSAP and Aethalometer demonstrated no sensitivity to gaseous adsorption. Although very similar in measurement principle, the PSAP and Aethalometer require markedly different correction factors, which is probably due to the different filter media used. Although on-site calibration of the PSAP and Aethalometer is advisable for best data quality, we recommend a set of "best practice" correction factors for ambient sampling based on the data from the present and previous studies. For this study, the estimated accuracies of the absorption coefficients determined by the PAS, PSAP and Aethalometer were 10, 15 and $20 \%$ (95\% confidence level), respectively.

Correspondence to: O. Schmid

(oschmid@mpch-mainz.mpg.de)

Published by Copernicus GmbH on behalf of the European Geosciences Union. 


\section{Introduction}

The Intergovernmental Panel on Climate Change (Penner et al., 2001) has identified radiative forcing by aerosols as one of the major uncertainties in the global radiation budget. While light scattered by aerosols cools the atmosphere (negative radiative forcing), absorbed electromagnetic radiation contributes to a positive radiative forcing. In addition to the direct heating of the atmosphere due to light absorption, there is a semi-direct effect as a result of the enhanced dissipation of clouds in the vicinity of heated aerosol layers (Ackerman et al., 2000; Penner et al., 2001). The latter may have significant implications on regional and global precipitation patterns. Despite its significance, light absorption by atmospheric aerosol is relatively poorly characterized in part due to a lack of reliable instrumentation.

Aerosol light scattering and absorption can be characterized by the scattering and absorption coefficients, $\sigma_{s}$ and $\sigma_{a}$, respectively, which describe the decrease of light intensity per distance and are therefore given in units of inverse meter (or here inverse megameter $1 \mathrm{Mm}^{-1}=10^{-6} \mathrm{~m}^{-1}$ ). For aerosols in the diameter range between $10 \mathrm{~nm}$ and $\sim 2.5 \mu \mathrm{m}$, as considered here, both $\sigma_{s}$ and $\sigma_{a}$ are complex functions of particle size and shape as well as the degree and kind of mixing with other particles (internally and externally mixed) (Bohren and Huffman, 1983; Fuller et al., 1999). While reliable in-situ measurement techniques for light scattering by aerosols have been available for several decades (Heintzenberg and Charlson, 1996), light absorption is by nature a more elusive property, since during the absorption process photons are converted into thermal energy, which makes it impossible to detect them directly. Historically, two main approaches have been applied to experimentally determine $\sigma_{a}$, namely the filter-based attenuation and the difference method (Horvath, 1993). The former involves deposition of aerosols onto a filter substrate and measuring the change in light attenuation through the filter as sample aerosol is deposited. Commercially available instruments of this type are the Aethalometer ${ }^{\mathrm{TM}}$ (Hansen et al., 1984) and Particle Soot Absorption Photometer (PSAP) (Bond et al., 1999). However, due to aerosol-filter interactions these instruments require site-specific calibration factors (Liousse et al., 1993; Petzold et al., 1997; Ballach et al., 2001; Arnott et al., 2005) that have most frequently been determined by intercomparison measurements with the difference method. The difference method determines light absorption of particles in their suspended state from the difference of extinction and scattering typically measured by an optical extinction cell and an integrating nephelometer, respectively. (Reid et al., 1998; Bond et al., 1999; Weingartner et al., 2003; Arnott et al., 2005). Employing the difference method for field studies is problematic due to the low absorption coefficients encountered under ambient conditions (frequently less than the detection limit of about $20 \mathrm{Mm}^{-1}$ ) and the large measurement uncertainties ( $>25 \%$; Schnaiter et al., 2005) for single scattering albedos typical for ambient aerosols (larger than 0.7). Recently, Petzold and Schoenlinner (2004) have introduced a novel filter-based absorption technique, the multiangle absorption photometer (MAAP), that measures not just light transmission through (as the Aethalometer and PSAP) but also angular reflection from an aerosol-laden filter and combines it with a two-stream-approximation radiative transfer scheme to account for filter-particle interactions (Petzold et al., 2005).

All methods described above are not only sensitive to light absorption but also to scattering effects that have to be adequately accounted for to yield reliable absorption values. In contrast, the photoacoustic spectrometer (PAS) (Truex and Anderson, 1979) is sensitive to absorption only, since it measures an acoustic signal that originates from the thermal response of irradiated particles due to light absorption. The measurements are performed on aerosols in their suspended state, i.e., filter artifacts do not occur. Recent laboratory calibration experiments with kerosene- and spark-generated soot have shown excellent agreement (better than 10\%) between the PAS and the difference method (Schnaiter et al., 2005; Sheridan et al., 2005; Virkkula et al., 2005). In addition, unlike any other absorption technique the PAS can be calibrated on-site with a calibration gas (Arnott et al., 2000).

This study is the first of two parts on spectral light absorption by ambient aerosols in the Amazon Basin measured during the SMOCC field campaign from 9 September to 14 November 2002. Part I reports on the field intercomparison of a $7-\lambda$ Aethalometer $(\lambda=450$ to $950 \mathrm{~nm})$ and a $1-\lambda$ PSAP $(565 \mathrm{~nm})$ with a $1-\lambda$ photoacoustic spectrometer (PAS, $532 \mathrm{~nm})$ as reference device. The principle, operation and performance of all three absorption instruments are briefly discussed and the multiple scattering and filter loading correction for the Aethalometer and PSAP are determined. Finally, for the latter two devices, the effects of relative humidity, single scattering albedo and gaseous adsorption onto the filter substrate are investigated. A detailed discussion of the spectral absorption properties of Amazonian aerosol will be provided in the Part II of this paper.

\section{Experimental}

\subsection{Measurement site and period}

¿From 9 September to 14 November 2002 the Large Scale Biosphere-Atmosphere Experiment in Amazonia - Smoke, Aerosols, Clouds, Rainfall and Climate (LBA-SMOCC) campaign was conducted in the state of Rondônia, Brazil (Andreae et al., 2004). The measurement station was located on the Fazenda Nossa Senhora Aparecida $\left(10.76^{\circ} \mathrm{S}\right.$, $62.32^{\circ} \mathrm{W}, 315 \mathrm{~m}$ a.s.l.), a pasture site in the south-western part of the Amazon Basin about $50 \mathrm{~km}$ north-west of JiParana $\left(10.88^{\circ} \mathrm{S}, 61.85^{\circ} \mathrm{W}, 235 \mathrm{~m}\right.$ a.s.l.; $\sim 110000$ inhabitants) (Andreae et al., 2002). While the area around 
FNS is predominantly grassland, the site is affected by the widespread vegetation fires due to fire-assisted land-clearing activities in the Amazon Basin during the dry season (JuneOctober). The measurement period was selected such that both dry season and wet season data could be collected. Here we will distinguish between three periods: the dry period from 9 September to 8 October (end of dry season), a dryto-wet transition period from 9 October to 30 October, and the wet period from 1 November to 14 November (beginning of wet season). While the dry period is heavily influenced by biomass burning events, this burning signature is significantly reduced in the transition period and reaches even lower levels in the wet season.

\subsection{Setup}

A comprehensive suite of aerosol, gas phase and meteorological parameters was measured during the SMOCC campaign. Here we focus on instrumentation for aerosol light absorption measurements. As mentioned above, aerosol light absorption was measured with three different instruments: a $1-\lambda$ photoacoustic spectrometer (PAS, $532 \mathrm{~nm}$ ), a 1- $\lambda$ Particle Soot Absorption Photometer (PSAP, Radiance Research, $565 \mathrm{~nm}$ ) and a 7- $\lambda$ Aethalometer (AE30, Magee Scientific, 450 to $950 \mathrm{~nm}$ ). In addition, two integrating $1-\lambda$ nephelometers (Radiance Research, M903, $545 \mathrm{~nm}$ ) were used to measure aerosol light scattering (Chand et al., 2006).

The aerosol inlets (Rupprecht \& Patashnick; inlet for the TEOM 1400) were located $\sim 1 \mathrm{~m}$ above the roof top of the instrument hut ( $\sim 7 \mathrm{~m}$ above the ground). They were equipped with a 1.5 or $10 \mu \mathrm{m}$ impactor, i.e., we sampled particulate matter either below 1.5 or $10 \mu \mathrm{m}$ aerodynamic diameter (PM1.5 and PM10, respectively).

The PSAP, PAS and one of the nephelometers were sampling from the same Rupprecht \& Patashnick PM10 inlet equipped with an additional $1.5 \mu \mathrm{m}$ impactor. Prior to particle detection the aerosol was dried to $R H<45 \%$ by a Nafion membrane counter-flow drier (Permapure, Inc.) and then passed through the $1.5 \mu \mathrm{m}$ impactor. The particle loss in the Nafion drier $\left(<5 \%\right.$ for $\left.50 \mathrm{~nm}<D_{p}<700 \mathrm{~nm}\right)$ and the cut-off characteristics of the $1.5 \mu \mathrm{m}$ impactor were experimentally determined after the campaign with dry ammonium sulfate particles. Both the absorption and scattering coefficient $\left(\sigma_{a}\right.$ and $\sigma_{s}$, respectively) were corrected for line losses (on average $\sim 2.5 \%$ ) utilizing the measured particle loss, the dry particle size distributions and the Mie code described by (Guyon et al., 2003a). Particle loss in the connecting stainless steel transport lines was considered negligible in the size range of interest for aerosol optical properties ( $30 \mathrm{~nm}$ to $10 \mu \mathrm{m}$ diameter), since for each instrument the length of the connecting tubing was below $10 \mathrm{~m}$ and the flow conditions were kept laminar. All flow rates were regularly calibrated to an estimated accuracy of about $2 \%$ with a positive displacement flow meter. The sampling flow rates of the PSAP, PAS and nephelometer were $0.2-0.4,0.8$ and $1.0-1.2 \mathrm{~L} \mathrm{~min}^{-1}$, respec- tively. Although the flow rates for the PSAP and nephelometer were smaller than specified by the manufacturer (to allow for more efficient drying of the sample flow and longer lifetime of the PSAP filter) we have not seen a systematic change in instrument response when the flow rate was increased to manufacturer specifications (PSAP: 1 to $4 \mathrm{~L} \mathrm{~min}^{-1}$; nephelometer: $10 \mathrm{~L} \mathrm{~min}^{-1}$ ). The time resolution of the PSAP, Aethalometer, PAS and nephelometers was $1 \mathrm{~min}, \sim 15 \mathrm{~min}$, $10 \mathrm{~s}$, and $1 \mathrm{~min}$, respectively. For the calibration of the PSAP and Aethalometer using the PAS, we converted all data to the sampling rate of the slowest device, the Aethalometer. The Aethalometer and the other nephelometer were operated with non-dried PM10 aerosol at a flow rate of about $6.6 \mathrm{~L} \mathrm{~min}^{-1}$ and $7 \mathrm{~L} \mathrm{~min}^{-1}$, respectively. We will refer to these operating conditions as "ambient", although the term "non-dried" is more accurate, since the absence of an active drying procedure led to operational relative humidities $(R H)$ that were somewhat lower than ambient $R H$ due to slightly elevated instrument temperatures, especially during nighttime. While during the dry and warm daytime conditions ambient and instrument $R H$ were within a few percent, the differences reached about $20 \%$ during nighttime when ambient $R H$ was close to $100 \%$, but instrument $R H$ only reached about $80 \%$.

Since the Aethalometer and the PAS were operated under different $R H$ conditions and from inlets with different cut-off diameters (PAS: PM1.5; Aethalometer: PM10), we have to consider these differences when comparing the Aethalometer with the PAS. The effect of $R H$ on Aethalometer performance is negligible as will be discussed below. Regarding the size cut-off we utilized the size-segregated aerosol mass information provided by a collocated MOUDI impactor (Marple et al., 1991). The relative mass contribution of the 1.8 to $10 \mu \mathrm{m}$ size segment (stage $2+3$ of the MOUDI impactor) to PM10 (stages 2 to 10) was on average $7.6 \%$ (dry period) and $14.9 \%$ (transition period). Considering that most of the absorbing material (black carbon) is found in PM1.5 and that the mass specific absorption cross section decreases with size for supermicron particles (Horvath, 1993), the cutoff-related systematic difference between Aethalometer and PAS signal is expected to be considerably less than 8 and $15 \%$ for the dry and transition period, respectively. We will see below that these difference are negligible compared to other effects. Since the PSAP and PAS were operated from the same inlet, no such considerations are necessary for the PSAP. Unless stated otherwise, all data are referenced to $1000 \mathrm{hPa}$ and $298.2 \mathrm{~K}$.

\subsection{Photoacoustic spectrometer (PAS)}

\subsubsection{Principle of operation}

The photoacoustic spectrometer (PAS) determines aerosol light absorption by converting the absorbed energy into an acoustic wave detected by a sensitive microphone (Terhune and Anderson, 1977). While passing aerosol through 
an acoustic resonator, a power-modulated laser periodically heats the aerosol, which leads to periodic thermal expansions and hence pressure pulses (acoustic wave). Using a calibrated microphone the pressure amplitude $P_{m}$ of this acoustic wave is measured and the nominal absorption coefficient $\sigma_{\text {PAS, raw }}$ can be calculated according to (Rosencwaig, 1980)

$\sigma_{\text {PAS }, \text { raw }}=P_{m} \frac{\pi^{2} A_{\text {res }} f_{0}}{P_{L} \tilde{Q}(\gamma-1)}$,

where $A_{\text {res }}, f_{0}$, and $\tilde{Q}$ are the cross sectional area, the acoustic resonance frequency, and the quality factor of the resonator, respectively, and $P_{L}$ and $\gamma$ are the modulated average laser power and the ratio of the isobaric and isochoric specific heats of the carrier gas $\left(\gamma_{\text {air }}=1.4\right)$, respectively.

\subsubsection{Technical details}

The device used here, a refined version of the PAS described by Arnott et al. (1999), was optimized for atmospheric applications by maximizing the signal to noise ratio. The PAS utilizes a frequency-doubled diode-laser-pumped Nd:YAG laser $(\lambda=532 \mathrm{~nm})$, which is power-modulated by a chopper at the resonance frequency of the acoustic resonator $\left(f_{0}=1500 \mathrm{~Hz}\right)$. The modulated laser power of $P_{L} \cong 60 \mathrm{~mW}$ is continuously monitored (after passing through the resonator) by a photodiode mounted on an integrating sphere. The length and crosssectional area of the resonator are $24.86 \mathrm{~cm}$ and $2.18 \mathrm{~cm}^{2}$, respectively. To avoid potential systematic errors due to temperature and pressure drifts in $f_{0}$ and $\tilde{Q}(\sim 75)$, both $f_{0}$ and $\tilde{Q}$ are continuously measured and optimized for acoustic resonance utilizing a piezoelectric disc. Since $P_{m}, P_{L}, f_{0}$ and $\tilde{Q}$ are directly measured by the PAS, all parameters of Eq. (1) are known and the absorption coefficient can be calculated without any device-specific calibration factor as typical for most filter-based absorption techniques. From the experimental uncertainties in these measurement parameters we estimated the overall uncertainty of $\sigma_{\text {PAS,raw }}$ as $5 \%$. To optimize the signal to noise ratio (and hence the lower detection limit) the acoustic noise was minimized passively by (1) using absorbing materials, (2) avoiding turbulent flow conditions and sharp bends in the connecting tubing, (3) installing an acoustic filter at the inlet of the resonator (two volumes with different acoustic resonance frequency, i.e., low and high pass filters in series) and (4) acoustically isolating the sample pump from the resonator by a critical orifice. It is also noteworthy that, while the sample flow rate (here $0.8 \mathrm{~L} \mathrm{~min}^{-1}$ ) affects the response time of the PAS (here: $<10 \mathrm{~s}$ ), it does not enter Eq. (1), i.e., the sample flow rate is irrelevant for the measured $\sigma_{a}$.

2.3.3 Calibration and intercomparison with difference method

In general the acoustic signal of the PAS may originate from absorbing particulate or gaseous components. Hence, in contrast to filter-based absorption techniques, photoacoustic sensors can be calibrated utilizing the well-known absorption properties of gaseous components. Recently, Arnott et al. (2000) have introduced a calibration procedure, which does not require any information beyond the data stream provided by the PAS itself. To rationalize this method it is important to note that during normal operation of the PAS, the extinction of the laser light in the acoustic resonator is due to both absorption and scattering effects by particulate and gaseous components, while the acoustic signal responds to absorption only. By introducing a particlefree absorbing calibration gas (here $\sim 1000$ ppm $\mathrm{NO}_{2}$ in air; $\sigma_{a} \sim 330000 \mathrm{Mm}^{-1}$ ) particulate effects are eliminated and the extinction of the laser light and the acoustic signal depend on gaseous effects only. Since for the calibration gas, scattering is small (Rayleigh scattering coefficient $\sim 10 \mathrm{Mm}^{-1}$ at normal conditions) compared to $\sigma_{a}$, both the mitigation of the laser light and the acoustic signal solely depend on absorption, i.e., Lambert-Beer's law can be used to derive a reference absorption value $\sigma_{L B}$

$P_{L}=P_{L, 0} \exp \left(-\sigma_{L B} L\right)$,

where $L(=0.2486 \mathrm{~m})$ is the optical length of the resonator and $P_{L}$ and $P_{L, 0}$ are the laser intensities with and without $\mathrm{NO}_{2}$ in the resonator, respectively, that can be determined by the photomultiplier of the PAS. It is evident from Eq. (2) that $\sigma_{L B}$ is completely independent of the photoacoustic signal of the PAS and that neither the concentration nor the absorption cross section of $\mathrm{NO}_{2}$ is required. The only requirement is that, on the one hand, the $\mathrm{NO}_{2}$ concentration is large enough to neglect Rayleigh scattering and to introduce a measurable change in $P_{L}$ and, on the other hand, the $\mathrm{NO}_{2}$ concentration is small enough not to exceed the linear response range of the microphone. As mentioned above, for the SMOCC campaign, we used $\sim 1000$ ppm of $\mathrm{NO}_{2}$ in synthetic air as calibration gas, which corresponded to an absorption coefficient of $\sigma_{\text {PAS, raw }} \sim 330000 \mathrm{Mm}^{-1}$. By progressively diluting the calibration gas with filtered air, we confirmed that the microphone was linear up to at least $330000 \mathrm{Mm}^{-1}$, i.e., over a dynamic range of more than five orders of magnitude.

Figure 1 illustrates a PAS calibration cycle where each of the data points represents an averaging period of $\sim 6 \mathrm{~s}$. The zero signal is determined with particle free air. When the particle free air is replaced by the calibration gas (at measurement point 10), the photoacoustically determined absorption coefficient $\left(\sigma_{\text {PAS,raw }}\right.$; see Eq. 1) increases abruptly from $0.5 \pm 1.2 \mathrm{Mm}^{-1}$ to $330000 \pm 3000 \mathrm{Mm}^{-1}$ (average and standard deviation), while the laser intensity (after passing through the resonator) decreases from $P_{L, 0}=61.631 \pm 0.009 \mathrm{~mW}$ to $P_{L}=56.870 \pm 0.014 \mathrm{~mW}$, which according to Eq. (2) corresponds to $\sigma_{L B}=323000 \pm 1000 \mathrm{Mm}^{-1}$. When at measurement point 24 the PAS is purged with particle free air again, both $\sigma_{\text {PAS, raw }}$ and $P_{L}$ return to their initial values. Comparing $\sigma_{\text {PAS,raw }}$ and $\sigma_{L B}$ we find that $\sigma_{\text {PAS,raw }}$ is $2.2 \%$ larger 


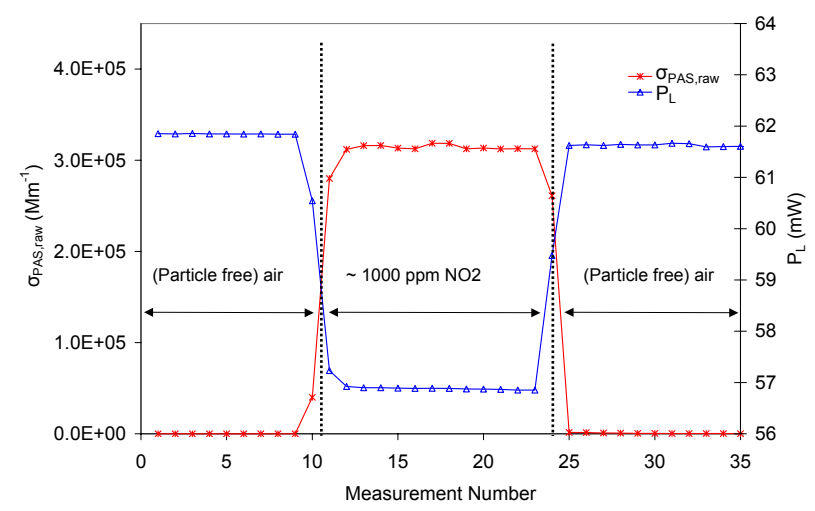

Fig. 1. Response of the PAS during a $\mathrm{NO}_{2}$ calibration cycle, where $\sigma_{\text {PAS,raw }}$ (stars) and $P_{L}$ (triangles) are the photoacoustically determined absorption coefficient and the laser power, respectively.

than $\sigma_{L B}$ (at a precision of $1.0 \%$ ), which is well within the estimated overall uncertainty of the PAS (5\%). Again we note that this simple two-point calibration procedure does not rely on any external calibration standard nor does it require exact knowledge of the $\mathrm{NO}_{2}$ concentration or any other information not provided by the data stream of the PAS.

As an additional measure of quality assurance we performed laboratory experiments with various types of aerosols comparing the absorption coefficient of the PAS to the difference of extinction $\left(\sigma_{e}\right)$ and scattering $\left(\sigma_{s}\right)$ determined by an optical extinction cell, the Long Path Optical Extinction Spectrometer (LOPES), and an integrating nephelometer (TSI, model 3563), respectively. To optimize the accuracy of the difference method, systematic biases due to e.g. the finite acceptance angle of the extinction cell and the angular non-idealities of the nephelometer were taken into account (Schnaiter et al. 2005). Figure 2 depicts the measured absorption coefficients for pure soot particles (solid symbols) and soot particles coated with non-absorbing materials (organic and inorganic; open symbols), where the organic coating was produced by ozonolysis of $\alpha$-pinene, which among other organic compounds generates pinic and pinonic acids (Saathoff et al., 2003). The absorption coefficients measured by the PAS and the difference method agree well for both pure soot particles (Diesel and spark-generated [PALAS] soot) and coated soot particles (slope $=0.972 \pm 0.022$ ). This confirms the results from a previous laboratory study which was performed on pure soot and biomass burning aerosols (Schnaiter et al., 2005).

\subsubsection{Data reduction and accuracy}

The main sources for systematic uncertainties of the PAS under field conditions are zero point instabilities and the crosssensitivity to ambient $\mathrm{NO}_{2}$. Since this may result in a variable zero-point offset, the instrument offset was repeatedly determined by zero calibrations using filtered (particle-free)

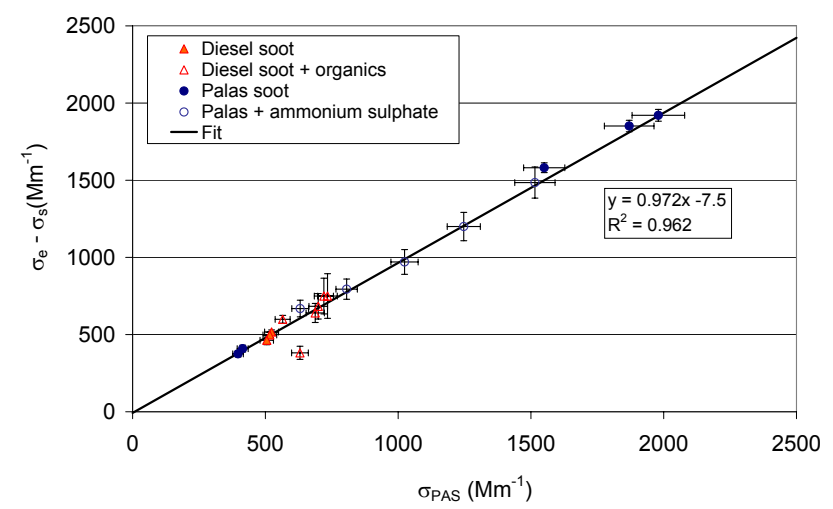

Fig. 2. Comparison of absorption coefficients determined by the PAS and the difference method (extinction minus scattering, $\sigma_{e}-$ $\sigma_{S}$ ) for both pure (Diesel and spark-generated (PALAS) soot) and coated soot particles (internally mixed aerosols).

ambient air for 10 to $30 \mathrm{~min}$ (at least) twice a day. We corrected for the $\mathrm{NO}_{2}$ cross-sensitivity utilizing the ambient $\mathrm{NO}_{2}$ mixing ratios continuously measured by a Model 42CTL NO/NO $\mathrm{N}_{\mathrm{x}}$ monitor (Thermo Environment Instruments Inc.) (Kirkman et al., 2002). For the same Nd:YAG laser as used here, Arnott et al. (2000) determined a $\mathrm{NO}_{2}$ specific absorption coefficient of $0.306 \pm 0.015 \mathrm{Mm}^{-1} \mathrm{ppb}^{-1}$ $\left(156000 \pm 1000 \mathrm{Mm}^{-1}\right.$ for $509000 \pm 25000 \mathrm{ppb}$ of $\left.\mathrm{NO}_{2}\right)$ at $846 \mathrm{hPa}$ and $294.7 \mathrm{~K}$. Hence, the $\mathrm{NO}_{2}$-induced PAS offset can be expressed as

$$
\begin{aligned}
\sigma_{\mathrm{NO} 2} & =0.306 \frac{p}{846 \mathrm{hPa}} \frac{294.7 \mathrm{~K}}{T} c_{\mathrm{NO} 2} \mathrm{Mm}^{-1} \mathrm{ppb}^{-1} \\
& =B_{\mathrm{NO} 2} \frac{p}{T} c_{\mathrm{NO} 2},
\end{aligned}
$$

where the lump constant $B_{\mathrm{NO} 2}$ equals $0.107 \pm 0.005 \mathrm{~K} \mathrm{hPa}^{-1} \mathrm{ppb}^{-1} \mathrm{Mm}^{-1}$ and $p, T$ and $c_{\mathrm{NO} 2}$ are the operating pressure, temperature and $\mathrm{NO}_{2}$ (volume) mixing ratio, respectively. Based on these considerations each time layer of the PAS data was corrected for zero offset and $\mathrm{NO}_{2}$ sensitivity according to

$\sigma_{\mathrm{PAS}}=\sigma_{\mathrm{PAS}, \mathrm{raw}}-\sigma_{0}-B_{\mathrm{NO} 2}\left(\frac{p}{T} c_{\mathrm{NO} 2}-\frac{p_{0}}{T_{0}} c_{\mathrm{NO} 2,0}\right)$,

where $\sigma_{\text {PAS, raw }}$ is given by Eq. (1) and $\sigma_{0}$ and $c_{\mathrm{NO} 2,0}$ are $\sigma_{\text {PAS, raw }}$ and $c_{\mathrm{NO} 2}$ during the PAS zero calibration, respectively. Since the zero calibration is performed with particlefree, but not $\mathrm{NO}_{2}$ denuded air, it is also necessary to include the $c_{\mathrm{NO} 2,0}$ term which accounts for the $\mathrm{NO}_{2}$ bias in $\sigma_{0}$. During the dry period of the SMOCC campaign, the period with the largest $\mathrm{NO}_{2}$ contribution, an average of $6.5 \%$ of the PAS signal could be attributed to $\mathrm{NO}_{2}$. However, since not the absolute $\mathrm{NO}_{2}$ concentration but the deviation from $c_{\mathrm{NO} 2,0}$ enters Eq. (4), the $\mathrm{NO}_{2}$ correction term was typically less than $1 \%$ of $\sigma_{\text {PAS }}$, except for a few instances where sudden drastic changes in pollution levels intermittently enhanced the $\mathrm{NO}_{2}$ correction term to up to $20 \%$. 
In addition to $\mathrm{NO}_{2}$ interference, the PAS data may be biased by (partial) aerosol volatilization due to laser-induced particle heating, since the latent heat of vaporization would reduce the amount of laser energy generating the acoustic wave and hence reduce the apparent $\sigma_{\text {PAS }}$ (Raspet et al., 2001). For a PAS similar to the one used here, Arnott et al. (2003) showed that for atmospheric aerosol with a deliquescence point of $R H \sim 60 \%$ the volatilisation effect was negligible $(<10 \%)$ up to $R H$ levels of about $80 \%$. Considering the relatively small average hygroscopic diameter growth during SMOCC ( $<1.04$ for $R H<45 \%$; (Rissler et al., 2006)), we anticipate no bias in the PAS signal due to water evaporation. This is corroborated by the absence of a phase shift between PAS microphone signal and oscillating laser power during the SMOCC campaign, which also indicates a negligible PAS bias due to mass transfer effects (Arnott et al., 2003).

Based on these considerations we estimate the accuracy of the PAS under field conditions as better than $10 \%(95 \%$ confidence level) for $\sigma_{\text {PAS }}>10 \mathrm{Mm}^{-1}$, which is larger than the $5 \%$ accuracy achieved under controlled laboratory conditions, since it includes the uncertainties due to unavoidable instabilities in operating conditions. For averaging periods of 5,15 and $60 \mathrm{~min}$, the instrument noise (precision) was $1.1,0.7$ and $0.4 \mathrm{Mm}^{-1}$ (95\% confidence level), respectively, which results in a lower detection limit (three times the $1 \sigma$ noise level) of $1.6,1.1$ and $0.6 \mathrm{Mm}^{-1}$, respectively.

\subsection{Aethalometer}

\subsubsection{Principle}

The 7- $\lambda$ Aethalometer (AE30, Magee Scientific) measures light attenuation $A T N$ at seven wavelengths (450, 571, 590, $615,660,880$, and $950 \mathrm{~nm}$, where the $571 \mathrm{~nm}$ channel had to be discarded for reasons discussed below) through an aerosol-laden quartz filter based on (Hansen et al., 1984)

$\mathrm{ATN}=100 \ln \left(\frac{I_{0}}{I}\right)$,

where $I$ and $I_{0}$ are the light intensities transmitted through the particle-laden and a blank spot of the filter, respectively. If aerosol is deposited onto the filter for a time period $\Delta t$, the attenuation coefficient $\sigma_{\text {ATN }}$ is given by

$\sigma_{\mathrm{ATN}}=\frac{A}{100 Q} \frac{\Delta \mathrm{ATN}}{\Delta t}$,

where $A$ is the area of the aerosol-laden filter spot and $Q$ is the volumetric sampling flow rate. The standard output protocol of the manufacturer provides equivalent black carbon mass concentration $B C_{\mathrm{ATN}}\left(\mathrm{g} \mathrm{m}^{-3}\right)$, which is determined from $\sigma_{\text {ATN }}$ according to

$$
B C_{\mathrm{ATN}}=\frac{\sigma_{\mathrm{ATN}}}{\alpha_{\mathrm{ATN}}}
$$

and

$\alpha_{\mathrm{ATN}}\left[m^{2} g^{-1}\right]=14625 / \lambda[\mathrm{nm}]$,

where the spectral mass specific attenuation cross-section $\alpha_{\text {ATN }}$ is based on a calibration at $880 \mathrm{~nm}$ utilizing the Malissa-Novakov method, a solvent-based thermal desorption method for elemental carbon analysis (Gundel et al., 1984). Since the reliability of thermal desorption methods is still under debate (Schmid et al., 2001), we avoid the resulting uncertainties by limiting our investigation to $\sigma_{\text {ATN }}$, the primary measurement parameter of the Aethalometer. Hence, each $15 \mathrm{~min} B C_{\mathrm{ATN}}$ value was converted into $\sigma_{\mathrm{ATN}}$ according to Eqs. (7) and (8).

\subsubsection{Relating attenuation and absorption}

It is well-known that $\sigma_{\text {ATN }}$ is generally larger than $\sigma_{a}$ due to optical interactions of the filter substrate with the deposited aerosol (Petzold et al., 1997; Kopp et al., 1999; Ballach et al., 2001; Weingartner et al., 2003; Arnott et al., 2005). The most significant filter-particle interactions and the resulting biases are: (1) multiple scattering of light at the filter fibers enhances the optical path length and hence imposes a positive bias on $\sigma_{\text {ATN }},(2)$ enhanced absorption of scattered light with increasing filter loading reduces the optical path length and hence reduces $\sigma_{\mathrm{ATN}}$, and (3) the filter reflectance (scattering in backwards hemisphere) and hence the measured ATN depends on the optical properties of the deposited particles (bias in $\sigma_{\text {ATN }}$ depends on physico-chemical properties of the particles).

Recently, Weingartner et al. (2003) (henceforth referred to as W2003) have shown that the absorption coefficient determined by the Aethalometer ( $\left.\sigma_{\text {aeth }}\right)$ can be expressed as

$\sigma_{\text {aeth }}=\frac{\sigma_{\mathrm{ATN}}}{C R(\mathrm{ATN})}$,

where the constant factor $C(\geq 1)$ corrects for multiple light scattering effects within the filter and $R(\mathrm{ATN})(\leq 1)$ accounts for the "shadowing" effect due to filter loading (decrease in Aethalometer sensitivity). Since the shadowing factor $(R)$ is small for lightly loaded filters $(\mathrm{ATN}<10), C$ can be determined from (W2003)

$C=\frac{\sigma_{10}}{\sigma_{\mathrm{PAS}}}$

where $\sigma_{10}$ represents all $\sigma_{\text {ATN }}$ values with $\mathrm{ATN}<10$ (i.e., $R \approx 1$ ) and $\sigma_{\text {PAS }}$ is the PAS-based (reference) absorption coefficient. Furthermore, the loading correction can be expressed as (W2003)

$R(\mathrm{ATN})=\left(\frac{1}{f}-1\right) \frac{\ln \mathrm{ATN}-\ln 10}{\ln 50-\ln 10}+1$,

where the shadowing factor $f$ is a parameter that depends on the type of aerosol and ATN is measured directly by the Aethalometer (W2003). Setting ATN=10 for all ATN values 
smaller than $10, R$ is equal to unity, i.e. the loading is so small that there is no effect of filter loading on the performance of the Aethalometer. On the other hand, for $\operatorname{ATN}>10, R$ decreases with ATN. The steepness of this decrease depends on the factor $f$. As seen from Eq. (11), if $f=1$ we find that $R$ is equal to unity independent of ATN, i.e. the aerosol deposited onto the filter has no effect on the Aethalometer performance. On the other hand, if $f>1$ we find that $R$ becomes smaller than unity, since the absorbing components of the deposited aerosol reduce the amount of multiple scattering within the filter matrix, i.e., $f$ can be described as "shadowing" parameter. For the SMOCC data, the factor $f$ can be determined by fitting Eq. (11) to the measured $R$ values given by

$R_{\text {meas }}(\mathrm{ATN})=\frac{\sigma_{\mathrm{ATN}}(\mathrm{ATN})}{\sigma_{\mathrm{PAS}} C}$.

Here $R_{\text {meas }}$ can be interpreted as the loading dependent Aethalometer sensitivity that is unity for a pristine filter and decreases with increasing filter loading.

\subsubsection{Effect of aerosol scattering on attenuation}

W2003 found no significant dependence of $\sigma_{\text {aeth }}(<1 \%)$ on the scattering component of the sample aerosol $\left(\sigma_{s}\right)$ for ammonium sulfate. The enhanced scattering effect (up to $5 \%$ ) for organic carbon particles produced by ozonolysis of $\alpha$ pinene was interpreted as an artifact due to a small (but unknown) absorption component of the organic carbon particles. On the other hand, Arnott et al. (2005) (henceforth referred to as A2005) reported a dependence of the Aethalometer signal on $\sigma_{s}$. The reason for this discrepancy is unknown, but we will see below, that it is irrelevant for the calibration performed here. Based on their findings A2005 suggested the following expression for the Aethalometer derived absorption coefficient $\sigma_{\text {aeth }}$

$\sigma_{\text {aeth }}=\frac{\sigma_{\mathrm{ATN}}-m_{s} \sigma_{s}}{C^{*} R(\mathrm{ATN})}$

where $m_{s}$ represents the fraction of the aerosol scattering coefficient $\sigma_{s}$ that is erroneously interpreted as absorption and $C^{*}$ and $R(\mathrm{ATN})$ are the multiple scattering and loading correction, respectively. The asterix on $C^{*}$ indicates that the magnitude of the multiple scattering correction introduced by A2005 differs from that defined by W2003 ( $C$ in Eq. 9) due to the scattering term. By equating Eqs. (13) and (9) (both equations refer to the absorption coefficient derived from the Aethalometer data) the relationship between $C$ and $C^{*}$ can be expressed as

$C^{*}=\frac{C\left(\sigma_{\mathrm{ATN}}-m_{s} \sigma_{s}\right)}{\sigma_{\mathrm{ATN}}}$.

Eq. (14) indicates that $C^{*}$ represents the multiple scattering correction $C$ corrected for aerosol scattering. Using the definition of the single scattering albedo

$\omega_{0}=\frac{\sigma_{s}}{\sigma_{s}+\sigma_{\text {aeth }}}$, we can substitute $\sigma_{s}$ in Eq. (14) by

$\sigma_{s}=\frac{\omega_{0}}{1-\omega_{0}} \sigma_{\text {aeth }}$,

yielding

$C^{*} \approx C\left[1-\frac{m_{s} \omega_{0}}{C\left(1-\omega_{0}\right)}\right]$,

where the approximation $\sigma_{\mathrm{ATN}} / \sigma_{\text {aeth }} \approx C$ was used, i.e., we neglected the loading factor $R$ (see Eq. 9), which is close to unity $(0.9 \pm 0.1$ at $532 \mathrm{~nm})$ as will be shown below. Equation (17) shows that the aerosol scattering effect $\left(m_{s}\right.$ term) increases with $\omega_{0}$ and decreases with $C$ (multiple scattering from the filter matrix). Obviously, in absence of aerosol scattering effects $\left(m_{s}=0\right.$ and/or $\left.\omega_{0}=0\right), C^{*}=C$.

Provided $m_{s}$ is known, Eq. (13) instead of Eq. (9) could be used for the field calibration of an Aethalometer. As mentioned above, while W2003 found no significant scattering effect $\left(m_{s}<0.01\right)$, A2005 reported much higher $m_{s}$ values of 0.052 (at $\lambda=521 \mathrm{~nm}$ ) for ammonium sulfate as challenge aerosol. Due to the considerable uncertainty in $m_{s}$, we will base our calibration efforts on Eq. (9), but use Eq. (17) to estimate the effect of aerosol scattering on the multiple scattering (filter matrix) correction $C$.

\subsubsection{Spectral dependence of calibration factors}

Since none of the seven Aethalometer channels $\left(\sigma_{\mathrm{ATN}, \mathrm{i}}\right.$ with $i=1,2, \ldots, 7)$ matches the wavelength of the PAS $\left(\lambda_{\mathrm{PAS}}=532 \mathrm{~nm}\right), \sigma_{\text {aeth }}\left(\right.$ and hence $\left.\sigma_{\mathrm{ATN}}\right)$ has to be converted to $\lambda$ PAS according to

$\sigma_{\mathrm{ATN}}=\sigma_{\mathrm{ATN}, 0}\left(\frac{\lambda_{\mathrm{PAS}}}{\lambda_{0}}\right)^{-\alpha_{\mathrm{ATN}}}$

where the attenuation Ångström exponent $\alpha_{\text {ATN }}$ was calculated from two Aethalometer channels using

$\alpha_{\mathrm{ATN}}=-\frac{\log \sigma_{\mathrm{ATN}, 0}-\log \sigma_{\mathrm{ATN}, 1}}{\log \lambda_{0}-\log \lambda_{1}}$.

Analogous to $\alpha_{\text {ATN }}$, the Ångström exponents of absorption $\left(\alpha_{a}\right)$ and scattering $\left(\alpha_{s}\right)$ are defined by replacing $\sigma_{\text {ATN }}$ by $\sigma_{a}$ and $\sigma_{s}$ in Eq. (19), respectively. Here, $\lambda_{0}$ and $\lambda_{1}$ were equal to 590 and $450 \mathrm{~nm}$, respectively, unless stated otherwise. For illustration of the $\lambda$-dependence of $\sigma_{\text {ATN }}$ and ATN, Fig. 3 depicts a time series of $\sigma_{\text {ATN }}$ (lines) and ATN (triangles) for three of the seven Aethalometer wavelengths, namely 450,590 and $880 \mathrm{~nm}$, represented by the colors blue, green and red, respectively. Once ATN $(590 \mathrm{~nm})$ reaches $\sim 75$, the Aethalometer automatically forwards the filter tape, ATN is set to zero (here at about 04:00) and the new filter spot remains exposed to the sample flow until ATN $(590 \mathrm{~nm})$ reaches $\sim 75$ again. Both $\sigma_{\text {ATN }}$ and ATN increase with decreasing wavelength. The average attenuation Ångström exponent $\alpha_{\mathrm{ATN}}$, derived from Eq. (19), was about 1.5. Please 


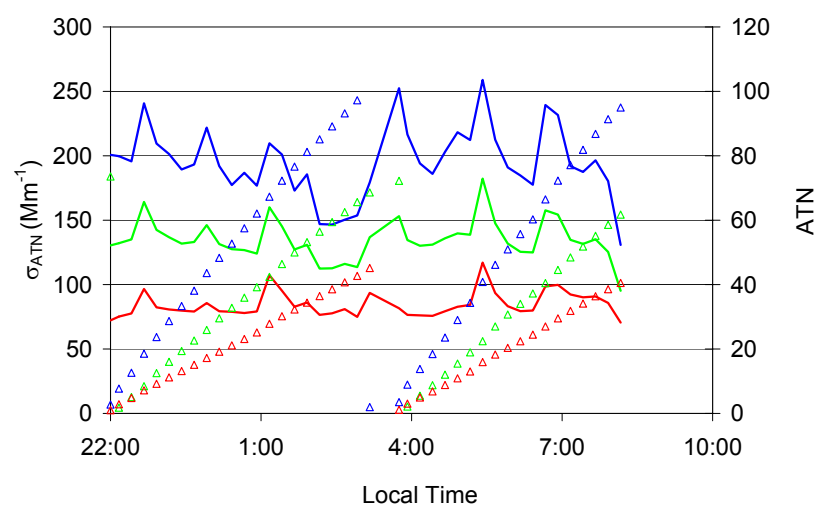

Fig. 3. Time series of attenuation coefficients (lines) and attenuation (triangles, secondary axis) for $\lambda=450,590$ and $880 \mathrm{~nm}$ (blue, green, and red, respectively).

note that the sensitivity of the Aethalometer decreases with increasing ATN. This can be seen from Fig. 3, where at about 04:00 the filter tape forwards and the $\sigma_{\text {ATN }}$ traces show a step-increase that is most pronounced for $\lambda=450 \mathrm{~nm}$, the trace with the larges ATN values. We will correct for this loading effect as described below.

Since our reference instrument operated at $\lambda_{\mathrm{PAS}}=532 \mathrm{~nm}$, we can only derive the Aethalometer correction factors $f$ and $C$ for $\lambda_{\text {PAs. }}$. Application of these factors to all seven Aethalometer channels my introduce systematic biases especially for $\lambda=950 \mathrm{~nm}$, the wavelength most different from $532 \mathrm{~nm}$. Hence, it is important to investigate the spectral dependence of $f$ and $C$.

For a wide variety of soot particles (internally/externally mixed; fresh/aged), W2003 showed that the dependence of the filter loading correction $R$ on ATN is independent of $\lambda$, i.e., the shadowing factor $f$ is a weak function of wavelength (see Eq. 11). While the mean $f$ values ranged from 1.15 to 1.65 depending on the type of challenge aerosol, $f$ was constant to within 0.09 (absolute) for a given aerosol type (W2003; excluding the atmospherically not relevant case for PALAS soot), i.e., for a given ATN value, $R$ was constant to within $11.8 \%$. Obviously, for $\mathrm{ATN}=0, R$ is equal to unity independent of $f$ and hence, averaged over an entire filter cycle, the effect of the wavelength dependence of $f$ on $R$ is considerably smaller than $10 \%$ even for the most affected channel $(450 \mathrm{~nm})$. Thus using a $\lambda$-independent $f$ value introduces Aethalometer biases much smaller than the calibration uncertainty ( $\sim 20 \%$; see Sect. 3.2.5) in any of the AE30 channels and hence, the wavelength dependence of $f$ is negligible for most atmospheric applications. In response to some recent misinterpretations of this finding (Kirchstetter et al., 2004) we emphasize again that this does not mean that the loading correction $(R)$ itself is wavelength independent. As seen from Eq. (11) $R$ increases with ATN and since ATN increases with decreasing $\lambda$ as seen from Fig. 3, $R$ increases towards the UV range.
Regarding the multiple scattering correction $C$, W2003 found only a minor difference of $<10 \%$ when comparing the 450 and $660 \mathrm{~nm}$ channels and they suggested that $C$ can be considered constant. A similarly modest dependence of $C^{*}$ on $\lambda$ (5\% increase from 470 to $660 \mathrm{~nm}$ ) was reported by A2005. However, in contrast to W2003, A2005 reported a non-negligible aerosol scattering correction factor $\left(m_{s}\right)$, i.e., $C$ and $C^{*}$ are not directly comparable. Hence, one should convert $C^{*}$ into the overall correction factor $C$ as given by Eq. (17)

$C=C^{*}+m_{s} \frac{\omega_{0}}{1-\omega_{0}}$.

A2005 provide $\lambda$-specific $C^{*}$ and $m_{s}$ values for a slightly different set of wavelengths as used here (see their Table 1 and our Table 1; they referred to $C^{*}$ and $m_{s}$ as $M$ and $\alpha$, respectively), but our $C^{*}$ and $m_{s}$ values at $532 \mathrm{~nm}$ are well approximated by their $521 \mathrm{~nm}$ values, i.e., for the purpose of this study we assume $C_{532}^{*}=C_{521}^{*}$ and $m_{s, 532}=m_{s, 521}$. Using Eqs. (15) and (16) we can describe the wavelength dependence of $\omega_{0}$ as

$$
\begin{aligned}
\omega_{0, \lambda} & =\frac{\sigma_{s, \text { ref }}\left(\frac{\lambda}{\lambda_{\text {ref }}}\right)^{-\alpha_{s}}}{\sigma_{s, \text { ref }}\left(\frac{\lambda}{\lambda_{\text {ref }}}\right)^{-\alpha_{s}}+\sigma_{a, \text { ref }}\left(\frac{\lambda}{\lambda_{\text {ref }}}\right)^{-\alpha_{a}}} \\
= & \frac{\omega_{0, \text { ref }}\left(\frac{\lambda}{\lambda_{\text {ref }}}\right)^{-\alpha_{s}}}{\omega_{0, \text { ref }}\left(\frac{\lambda}{\lambda_{\text {ref }}}\right)^{-\alpha_{s}}+\left(1-\omega_{0, \text { ref }}\right)\left(\frac{\lambda}{\lambda_{\text {ref }}}\right)^{-\alpha_{a}}},
\end{aligned}
$$

where we assumed that $\sigma_{s}$ and $\sigma_{a}$ scale according to $\lambda^{-\alpha_{s}}$ and $\lambda^{-\alpha_{a}}$, respectively, with $\alpha_{s}$ and $\alpha_{a}$ being the Ångström exponents for scattering and absorption, respectively. Here, the reference wavelength $\lambda_{\text {ref }}$ is $532 \mathrm{~nm}$ (or $521 \mathrm{~nm}$, if the data by A2005 are used). For the SMOCC data, $\omega_{0, \text { ref }}=0.92$ and $\alpha_{s}=2$ (Chand et al., 2006). Choosing a reasonable range of Angström exponents for absorption $\left(\alpha_{a}=1,1.5\right.$ or 2) (Kirchstetter et al., 2004) we can now calculate $C$ from Eqs. (20) and (21) for wavelengths between 370 and $950 \mathrm{~nm}$ as given in Table 1 . Obviously, $C$ increases with $\lambda$, but the degree of increase depends on $\alpha_{a}$. To parameterize this dependence we have plotted $\ln (C)$ versus $\ln (\lambda / \mathrm{nm})$ for $\alpha_{a}=1$, 1.5 or 2 (see Fig. 4a) and performed a quadratic fit for each $\alpha_{a}$ value

$$
\ln (C)=A(\ln (\lambda / \mathrm{nm}))^{2}+B \ln (\lambda / \mathrm{nm})+D .
$$

Since Eq. (22) can be transformed into

$$
\frac{C}{C_{\mathrm{ref}}}=\frac{\lambda^{A \ln (\lambda / \mathrm{nm})+B}}{\lambda_{\mathrm{ref}}^{A \ln \left(\lambda_{\mathrm{ref}} / \mathrm{nm}\right)+B}},
$$

the dependence of $C$ on $\lambda$ can be expressed by the coefficients $A$ and $B$ that depend on $\alpha_{a}$, where again for the SMOCC data $\lambda_{\text {ref }}=532 \mathrm{~nm}$. As seen from Fig. $4 \mathrm{~b}$ a quadratic 
Table 1. Calculation of $C$ according to Eq. (20) using $C^{*}$ and $m_{s}$ as given by A2005 (Arnott et al., 2005). For $\omega_{0}$ (521 nm) and $\alpha_{S}$ we assumed 0.92 and 2 , respectively.

\begin{tabular}{cccccccccccc}
\hline & \multicolumn{4}{c}{$C$ at various wavelengths $(\mathrm{nm})$} & \multicolumn{3}{c}{ Ratios of $C$ for various wavelength pairs } \\
\hline$\alpha_{a}$ & 370 & 470 & 521 & 590 & 660 & 880 & 950 & $660 / 470$ & $660 / 521$ & $521 / 470$ & $950 / 521$ \\
1 & 2.355 & 2.656 & 2.677 & 2.730 & 2.827 & 2.933 & 2.925 & 1.065 & 1.056 & 1.008 & 1.093 \\
1.5 & 2.270 & 2.626 & 2.677 & 2.770 & 2.909 & 3.144 & 3.179 & 1.107 & 1.087 & 1.019 & 1.187 \\
2 & 2.198 & 2.599 & 2.677 & 2.812 & 3.000 & 3.420 & 3.523 & 1.154 & 1.121 & 1.030 & 1.316 \\
\hline
\end{tabular}

${ }^{1}$ The parameters $C^{*}$ (and $m_{S}$ ) were taken from the Table 1 of A2005 (they referred to $C^{*}$ and $m_{S}$ as $M$ and $\alpha$, respectively) and given here in ascending order of wavelength (from 370 to $950 \mathrm{~nm})$ : 1.813 (0.0335), 2.073 (0.0457), $2.076(0.0523), 2.104$ (0.0616), $2.182(0.0713)$, 2.226 (0.1038), 2.199 (0.1148).

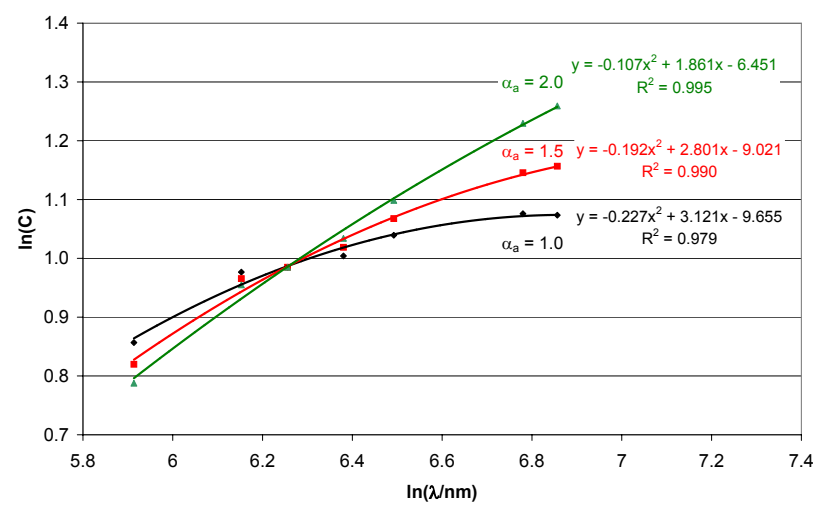

Fig. 4a. Double logarithmic plot of $C$ versus $\lambda$ for absorption Ångström exponents $\alpha_{a}=1.0$ (black), 1.5 (red) and 2.0 (green). The symbols represent the data by A2005 (see Table 1) and the lines are quadratic fits.

fit of $A$ and $B$ versus $\alpha_{a}$ provides

$A=0.102 \alpha_{a}^{2}-0.187 \alpha_{a}-0.141$ and

$B=-1.275 \alpha_{a}^{2}+2.564 \alpha_{a}+1.827$,

respectively. Using Eqs. (23) and (24) we can now determine $C$ for any given $\lambda$ and $\alpha_{a}$. The good agreement between calculated and measured $C$ values is depicted in Fig. $4 \mathrm{c}$ that compares the $C$ values listed in Table 1 (normalized to $C_{521}$ ) and the corresponding fit curves for $\alpha_{a}=1,1.5$ or 2 . The maximum deviation between data and fit is less than $3 \%$. We note as caveat that Eq. (24) was derived for the parameters of the SMOCC data $\left(\omega_{0, \text { ref }}=0.92\right.$ and $\left.\alpha_{s}=2\right)$, but the procedure described here can be applied to any set of $\omega_{0, \text { ref }}$ and $\alpha_{s}$ values.

\subsection{PSAP}

The Particle Soot Absorption Photometer (PSAP; Radiance Research) described by Bond et al. (1999) (henceforth referred to as B1999) measures aerosol light absorption at nominally $565 \mathrm{~nm}$ from the light transmitted through an aerosol-laden quartz filter, very similar to the principle of the Aethalometer. Using the difference method (at $550 \mathrm{~nm}$ )

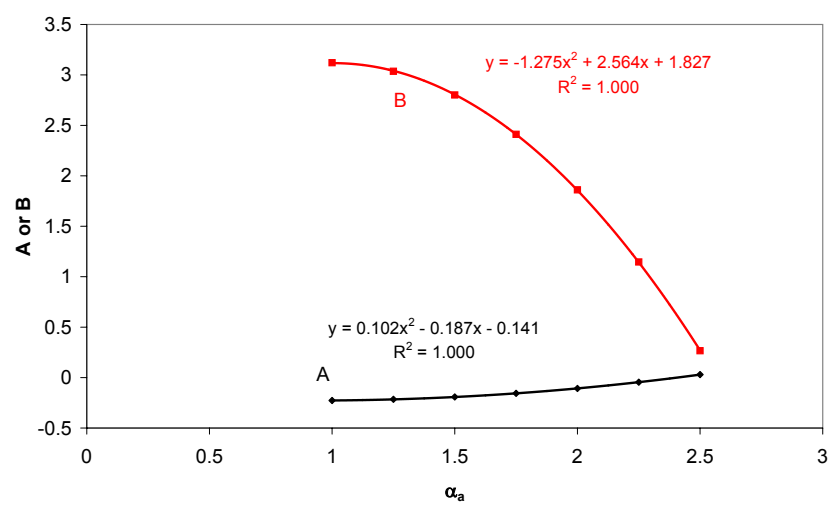

Fig. 4b. Dependence of the coefficients A and B (see Eq. (23)) on the absorption Ångström exponent $\left(\alpha_{a}\right)$.

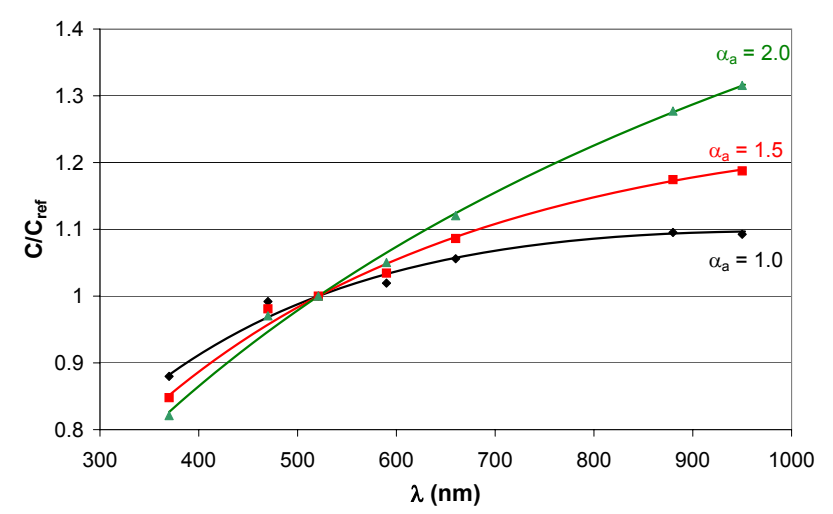

Fig. 4c. Spectral dependence of $C$ normalized to $C_{\text {ref }}$ (here $C_{521}$ ) for three different absorption Ångström exponents $\alpha_{a}=1.0,1.5$ and 2.0. The symbols and lines represent the data (as given in Table 1) and curve fits (see Eqs. (23) and (24)), respectively.

as reference B1999 calibrated the PSAP with pure nigrosin and ammonium sulfate particles as well as internal mixtures of both. Analogous to the calibration equation used for the Aethalometer (see Eq. 13) they found 


$$
\begin{aligned}
\sigma_{\mathrm{PSAP}, \mathrm{Bond}} & =\frac{\sigma_{\text {raw }, \mathrm{PSAP}} K_{Q} K_{A}-K_{1} \sigma_{s}}{K_{2}} \\
& =\frac{\sigma_{\text {raw,PSAP }} K_{Q} K_{A}}{K_{2}+K_{1} \frac{\omega_{0}}{1-\omega_{0}}},
\end{aligned}
$$

where $\sigma_{\text {raw,PSAP }}$ is the absorption coefficient reported by the PSAP (includes a manufacturer-provided filter loading correction (B1999)), $K_{Q}$ and $K_{A}$ are the correction factors for flow rate and sample deposit area, respectively, and the calibration constants $K_{1}$ and $K_{2}$ are given by $K_{1}=0.02 \pm 0.02$ and $K_{2}=1.22 \pm 0.2$ (95\% confidence level), respectively. The last expression in Eq. (25) was derived by applying Eq. (16), where $\sigma_{\text {ath }}$ was substituted by $\sigma_{\text {raw,PSAP. During SMOCC }}$ we used the PSAP output signal ( $\sigma$ raw,PSAP $)$ given on a logarithmic voltage scale and the flow rate was artificially set to a constant internal value of $0.5 \mathrm{~L} \mathrm{~min}^{-1}$, which did not correspond to the true flow rate, but made it simple to correct for the true flow rate $Q$ by using $K_{Q}=0.5 / Q( \pm 3 \%)$, where $Q$ is given in $\mathrm{L} \mathrm{min}^{-1}$. Similarly the true diameter of the sample deposit spot $(4.86 \pm 0.20 \mathrm{~mm})$ deviated from the internally assumed value of $5.1 \mathrm{~mm}$, which resulted in $K_{A}=(4.86 / 5.1)^{2}=0.91 \pm 0.07$. Comparing to Virkkula et al. (2005a) (henceforth referred to as V2005a) who measured $K_{A}=0.97 \pm 0.04$ we find that this is within the reported unit-to-unit variability of about $20 \%$ (Reid et al., 1998; Anderson et al., 1999; Mader et al., 2002; Wex et al., 2002; Arnott et al., 2003; Guyon et al., 2003a, b).The fact that $K_{2}$ does not depend on ATN implies that the loading correction provided by the manufacturer was confirmed at least up to $\mathrm{ATN}=35$ (which corresponds to a transmittance of 0.7). The Bond correction effectively converts the PSAP wavelength from 565 to $550 \mathrm{~nm}$, since their reference device operated at $550 \mathrm{~nm}$. Although B1999 recommend a minimum PSAP filter transmittance of 0.7 (ATN=35), we found no bias down to $0.5(\mathrm{ATN}=70)$ a result that was also reported by V2005a and Guyon et al. (2003b). Hence we included all data with ATN $<70$ in the present study. Assuming the uncertainties in $K_{Q}, K_{A}, K_{1}$ and $K_{2}$ are purely random and applying the laws of error propagation to Eq. (25) the accuracy (95\% confidence level) of the Bond correction is given by

$$
\begin{aligned}
& \frac{\Delta \sigma_{\mathrm{PSAP}, \text { Bond }}}{\sigma_{\mathrm{PSAP}, \text { Bond }}}= \\
& \sqrt{\left(\frac{\Delta K_{Q}}{K_{Q}}\right)^{2}+\left(\frac{\Delta K_{A}}{K_{A}}\right)^{2}+\frac{\left(\Delta K_{2}\right)^{2}+\left(\Delta K_{1} \frac{\omega_{0}}{1-\omega_{0}}\right)^{2}}{\left(K_{2}+K_{1} \frac{\omega_{0}}{1-\omega_{0}}\right)^{2}}} .
\end{aligned}
$$

For an average $\omega_{0}$ of 0.92 (as applicable for the SMOCC data), we can estimate the accuracy of the Bond corrected SMOCC data as $23 \%$ using the uncertainties of $K_{Q}, K_{A}, K_{1}$ and $K_{2}$ given above.

\section{Intercomparison and field calibration of PSAP and Aethalometer}

For the field calibration of the PSAP and Aethalometer with the PAS, we only included PAS data that showed no statistically significant zero drift for three consecutive zero calibrations, which typically occurred over the course of $24 \mathrm{~h}$. This resulted in about 105 and $95 \mathrm{~h}$ of calibration data from the dry (17 September to 8 October) and transition (9 to 30 October) period, respectively. Since we observed no significant dependence of the calibration factors on period, we based the PSAP and Aethalometer calibration on the entire $200 \mathrm{~h}$ of PAS data. Due to the low pollution levels throughout the wet period of the SMOCC campaign, the wet period is excluded from the PSAP and Aethalometer calibration, but will be discussed separately below.

\subsection{PSAP}

As a first approximation we applied the Bond correction (Eq. 25) to the PSAP using the (dry) scattering coefficients (at $545 \mathrm{~nm}$ ) determined by the nephelometer connected to the same inlet as the PSAP. Performing a linear regression on 5 min averages of $\sigma_{\text {PSAP, Bond }}$ and $\sigma_{\text {PAS }}$ we found a slope of $0.76\left(R^{2}=0.813\right)$, i.e., changes in PSAP response were on average about $24 \%$ lower than changes in $\sigma_{\text {PAS }}$ (data not shown). Accounting for the difference between the reference wavelength of the Bond correction $(550 \mathrm{~nm})$ and the PAS $(532 \mathrm{~nm})$ using a $\lambda^{-1.5}$ dependence reduced the slope to 0.72 , which is outside the $95 \%$ confidence level of the Bond correction $(\sim 23 \%)$. On the other hand, our analysis revealed no systematic dependence of $\sigma_{\mathrm{PSAP}}$, Bond on either filter loading $(\mathrm{ATN}<70)$ or particle single scattering albedo, i.e., the Bond correction adequately accounted for these effects. However, we found a systematic dependence on operating $R H$ and temperature (T) as well as on $\sigma_{\mathrm{PAS}}$ and $\sigma_{s}$. As seen from Fig. 5a, the ratio of $\sigma_{\mathrm{PSAP}}$, Bond and $\sigma_{\mathrm{PAS}}$ was about constant for $35<R H<45 \%$ ( $\sigma_{\mathrm{PSAP}, \mathrm{Bond}} / \sigma_{\mathrm{PAS}}=1.18$; or 1.24 , if the PAS is corrected to $550 \mathrm{~nm})$. On the other hand, for low $R H$ between $20 \%$ and $30 \%, \sigma_{\mathrm{PSAP}, \mathrm{Bond}} / \sigma_{\mathrm{PAS}}$ monotonically decreased with $R H$ down to about 0.67 ( 0.70 for $550 \mathrm{~nm}$ ). As seen in Fig. 5b, a similar trend is observed for T, where $\sigma_{\mathrm{PSAP}, \mathrm{Bond}} / \sigma_{\mathrm{PAS}}$ is positively correlated to T between 24 and $26^{\circ} \mathrm{C}$ and then remains about constant (slight negative correlation) for $26^{\circ} \mathrm{C}<\mathrm{T}<31^{\circ} \mathrm{C}$. It is important to note that during the SMOCC campaign all low $R H$ and $\mathrm{T}$ data were gathered during night due to a higher efficiency of the Nafion drier and lower ambient temperatures. Consequently, most of the low and high $\sigma_{\mathrm{PSAP} \text {, Bond }} / \sigma_{\mathrm{PAS}}$ values resulted from nighttime and daytime measurements, respectively. Hence, any parameter that shows a significant diel variation will correlate with $\sigma_{\mathrm{PSAP}, \text { Bond }} / \sigma_{\mathrm{PAS}}$. This includes $\sigma_{\mathrm{PAS}}$ and $\sigma_{s}$, since we consistently observed elevated pollution levels during nighttime due to the formation of a shallow nocturnal boundary layer (Rissler et al., 2006). Since $R H, \mathrm{~T}, \sigma_{\mathrm{PAS}}$ and 
$\sigma_{s}$ are not independently varying parameters, it is not clear which of these parameters (or any other parameter with a pronounced diel variation) is mainly responsible for the observed systematic trend in the PSAP data (see Figs. 5a and b). However, laboratory measurements indicate that $\sigma_{\mathrm{PSAP}, \mathrm{Bond}}$ does not depend on $\sigma_{\mathrm{PAS}}$ or $\sigma_{s}$ (V2005a). To our knowledge a rigorous investigation of a potential PSAP sensitivity to $R H$ and $\mathrm{T}$ has not been performed yet. A more detailed discussion of this issue will be provided below (Sect. 4). For now, we point out that our data do not conclusively identify a specific parameter as cause for the observed bias.

On the other hand, the correlation with both $R H$ and $\mathrm{T}$ is strong enough to provide reasonably accurate correction factors for the observed trends. Choosing $R H$ as governing parameter the correction factor $K_{R H}$ was determined by fitting the normalized PSAP data to a second order polynomial (solid line in Fig. 5a)

$$
\begin{aligned}
K_{R H} & =\sigma_{\mathrm{PSAP}, \text { Bond }} / \sigma_{\mathrm{PAS}} \\
& =-0.9212+0.1047 R H-0.0013 R H^{2},
\end{aligned}
$$

where $R H$ varies between 20 and 43\%. For $R H>43 \%$ we used $K_{R H}=K_{43}=1.18$. Hence, the PSAP-derived absorption coefficient $\sigma_{\text {PSAP }}$ (converted to $\lambda_{\text {PAS }}=532 \mathrm{~nm}$ ) was calculated from $\sigma_{\mathrm{PSAP}}=\sigma_{\mathrm{PSAP}, \mathrm{Bond}} / K_{R H}$. Figure $5 \mathrm{c}$ shows excellent correlation $\left(R^{2}=0.954\right)$ and agreement (slope $=0.945 \pm 0.042$ ) of $\sigma_{\text {PSAP }}$ with $\sigma_{\mathrm{PAS}}$, where we neglected PAS values smaller than $4 \mathrm{Mm}^{-1}$ to avoid potentially large uncertainties near the lower detection limit. Hence, applying an $R H$-dependent correction factor $\left(K_{R H}\right)$ to the Bond-corrected PSAP data adequately accounts for the PSAP artifacts observed during SMOCC. It is also noteworthy that during nighttime $R H$ (and T) oscillated on a time scale of about $25 \mathrm{~min}$ and an amplitude of $\sim 1.0 \%$ (absolute) due to fluctuations in the room temperature (airconditioner turned periodically on and off). These $R H$ (and T) oscillations frequently (not always) induced oscillations in $\sigma_{\mathrm{PSAP}, \mathrm{Bond}}$ that were significantly larger than predicted by Eq. (27). We eliminated these oscillations by applying a running average over one oscillation period. The fit parameters given by Eq. (27) are based on these oscillation-corrected data. After removal of these oscillations we did not observe any systematic difference between day and night data that could not be described by the single $R H$ correction equation given above. We estimate the accuracy and precision (95\% confidence level) of $\sigma_{\text {PSAP }}(532 \mathrm{~nm})(5$-min averages) as about $15 \%$ and $12 \%$, respectively.

\subsection{Aethalometer}

As mentioned above the operating conditions of the Aethalometer (AE30) differed from those of the PAS in that the Aethalometer was sampling under ambient conditions (no drier) from a $10 \mu \mathrm{m}$ inlet (PAS: $1.5 \mu \mathrm{m}$ impactor). Based
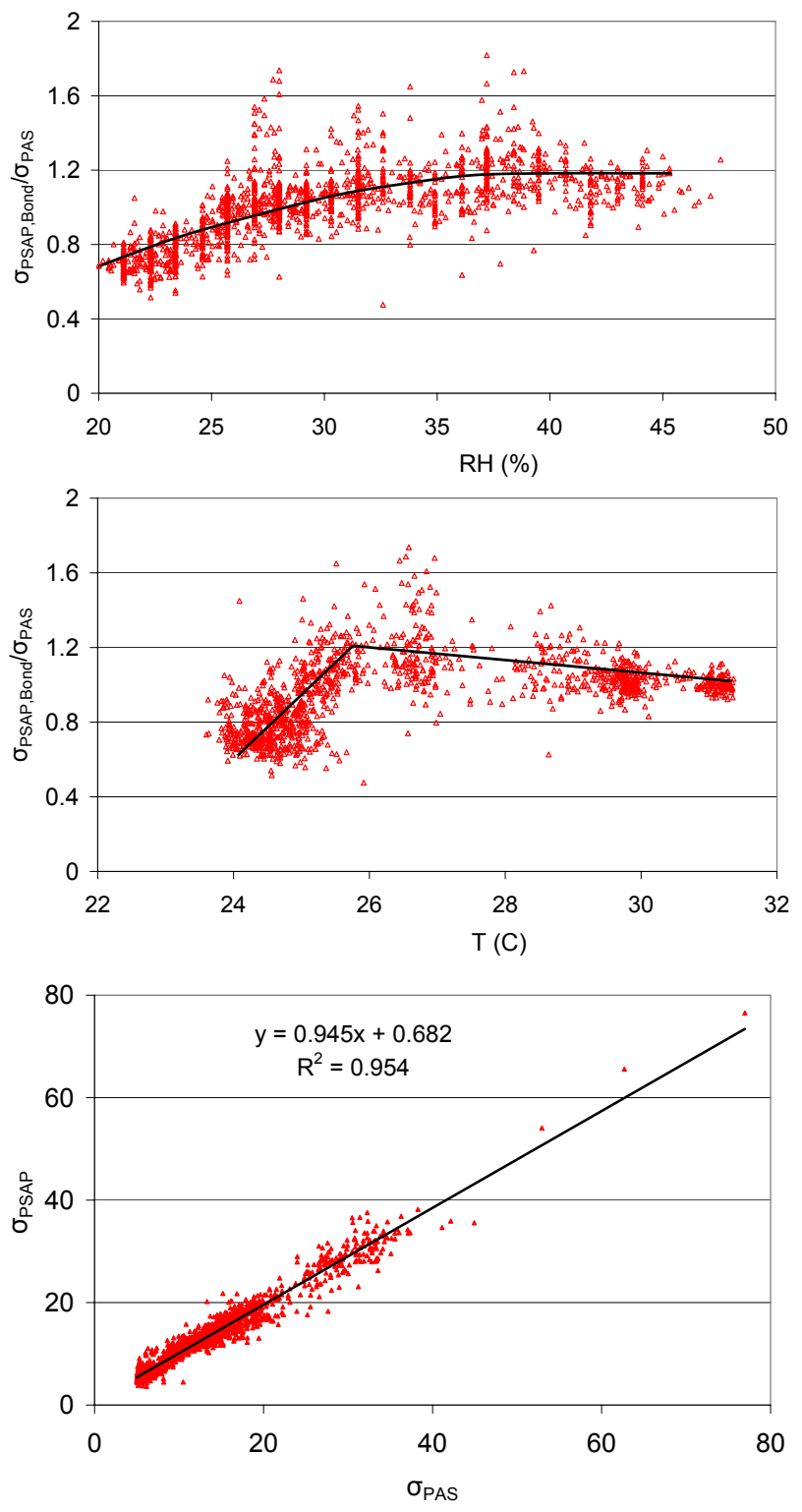

Fig. 5. (a) and (b) Dependence of the Bond corrected normalized PSAP absorption coefficient on relative humidity $(R H)$ and operating temperature $(\mathrm{T})$, respectively. (c) Correlation of the Bond and $R H$ corrected PSAP absorption coefficient $\sigma_{\text {PSAP }}$ with $\sigma_{\text {PAS }}$.

on MOUDI impactor data the average effect of the different cut-off diameters on total aerosol absorption has been estimated as less than 8 and $15 \%$ for the dry and transition period, respectively. A potential systematic effect of $R H$ on the Aethalometer performance will be investigated below.

For the following analysis, the $590 \mathrm{~nm}$ channel of the Aethalometer was converted to $532 \mathrm{~nm}$ according to Eqs. (18) and (19) using $\lambda_{1}=450, \lambda_{0}=590 \mathrm{~nm}$ and $\lambda_{\text {PAS }}=532 \mathrm{~nm}\left(=\lambda_{\text {ref }}\right)$. Although the AE30 has a $571 \mathrm{~nm}$ channel that is even closer to $532 \mathrm{~nm}$ than the $590 \mathrm{~nm}$ 


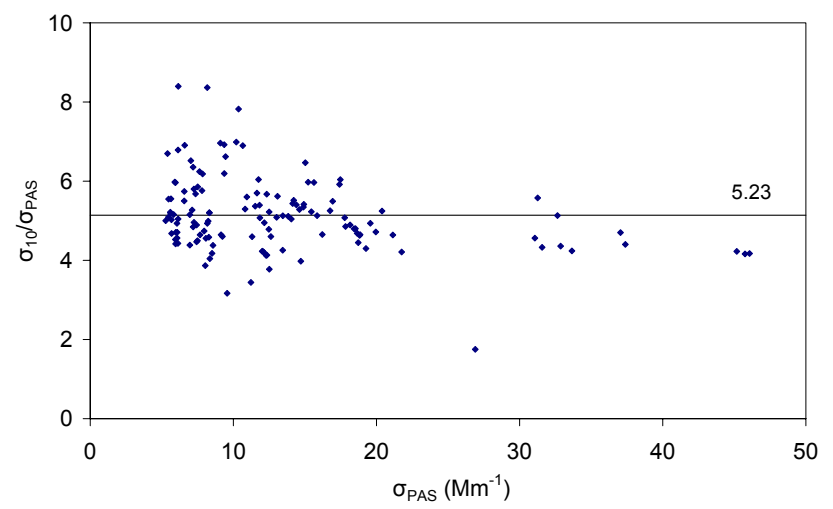

Fig. 6. Experimental determination of the multiple scattering factor $C_{532}$ for the Aethalometer according to Eq. (10). The solid line represents the arithmetic mean $(=5.23)$ of the ratio of $\sigma_{10}$ and $\sigma_{\text {PAS }}$ at $532 \mathrm{~nm}$.

channel, it had to be discarded, since for unknown reasons it was consistently too low by about $20 \%$.

\subsubsection{Multiple scattering and loading correction}

Following Eq. (10) the multiple scattering correction factor $C_{532}=5.23 \pm 0.17$ was determined from the arithmetic mean ( $95 \%$ confidence level of the mean) of the ratios of $\sigma_{10}$ and $\sigma_{\text {PAS }}$ (see Fig. 6), where again we limited $\sigma_{\text {PAS }}$ to values larger than $4 \mathrm{Mm}^{-1}$. The multiple scattering correction is by far the most important effect when inferring $\sigma_{\text {aeth }}$ from $\sigma_{\mathrm{ATN}}$.

The effect of filter loading on Aethalometer sensitivity is depicted in Fig. 7. Each measurement cycle of the Aethalometer begins with an acclimatization phase during which a pristine spot of the filter tape is put into place and the measured ATN (triangles) is defined as 0, i.e., the light intensity $(I)$ measured through the sample spot is set equal to the intensity transmitted through a clean reference spot $\left(I_{0}\right.$, see Eq. 5). With continuing exposure to the sample flow increasing amounts of (absorbing) aerosol deposit onto the filter spot and the resulting "darkening" of the filter progressively increases the light attenuation ATN (open triangles). At a predefined ATN value of $\sim 75(\lambda=590 \mathrm{~nm})$ the filter tape is automatically forwarded to expose a new pristine filter spot $(\mathrm{ATN} \sim 0)$ to the sample flow and the cycle starts again. Figure 7 shows a time series of five consecutive filter changes. For each time layer, we calculated the Aethalometer sensitivity ( $R_{\text {meas }}$; solid diamonds) from Eq. (12) using $C_{532}=5.23$. Fitting the numerical expression of the sensitivity ( $R(\mathrm{ATN})$; see Eq. 11$)$ to $R_{\text {meas }}$ yields the fit parameter $f=1.20$, where we set $R(\mathrm{ATN})=1$ for ATN $<10$ to be consistent with the assumption adopted for determining $C_{532}$ from Eq. (10). For comparison, we also plotted the fit based on the more rigorously derived form of the loading correction presented by A2005 (dashed line; see their Eq. 27) that shows a very similar result. As seen in Fig. 7, the loading effect accounts for a maximum sensitivity reduction of about $20 \%$ at $532 \mathrm{~nm}$. The

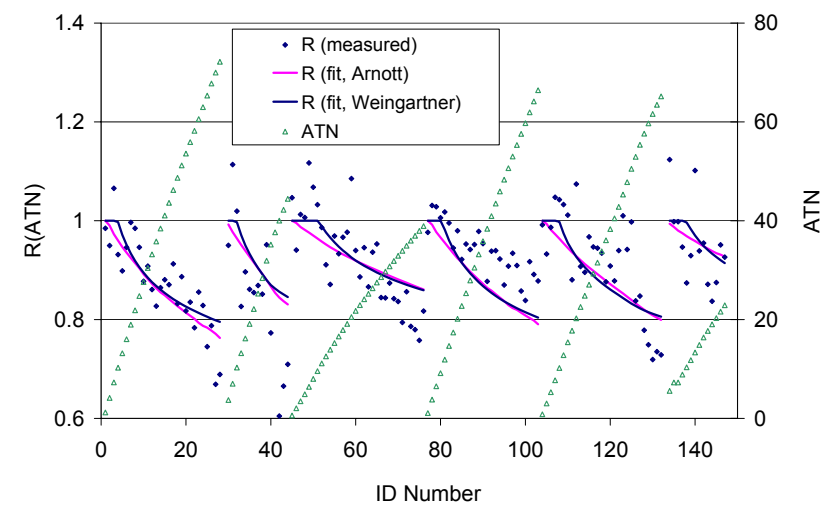

Fig. 7. Illustration of the effect filter loading (ATN, open triangles) on Aethalometer sensitivity $(R)$ for the $590 \mathrm{~nm}$ channel converted to $532 \mathrm{~nm}$ (data points were numbered consecutively). The measured sensitivity (solid diamonds) was fitted according to the expressions provided by Weingartner et al. (2003) (blue line) and Arnott et al. (2005) (magenta line).

poor correlation coefficient between data and fit $\left(R^{2} \sim 0.5\right)$ is a result of the relatively small effect of filter loading $(<20 \%$ at $532 \mathrm{~nm}$ ) compared to the multiple scattering correction factor of 5.23. Hence, small fluctuations in $C_{532}$ may obfuscate the filter loading effect. As discussed below possible culprits for such fluctuations are instrument instabilities and sensitivities to $R H, \omega_{0}$, and gaseous adsorption.

With $C_{532}=5.23$ we can now use Eqs. (23) and (24) to find $C_{\lambda}$ and hence use Eqs. (9) and (11) to convert $\sigma_{\text {ATN }}$ to $\sigma_{\text {aeth }}$ for each Aethalometer channel (as mentioned above, $f=1.20$ is independent of $\lambda$ ) provided the Ångström exponents for absorption $\left(\alpha_{a}\right)$ is known. However, since $\alpha_{a}$ is not known, we use the following iterative procedure: 1) use $\alpha_{\text {ATN }}$ (from Aethalometer data) as first approximation for $\left.\alpha_{a}, 2\right)$ calculate $\sigma_{\text {aeth, } \lambda}$ from Eqs. (9) and (11) and (23), 3) derive a refined $\alpha_{a}$ value based on $\sigma_{\text {aeth, } \lambda}$ and 4) repeat steps 2 and 3 until $\sigma_{\text {aeth }, \lambda}$ converges. During the SMOCC campaign, $\alpha_{\text {ATN }}$ was typically around 1.5. Applying the above procedure we find $\alpha_{a}=1.82,1.91,1.94$ and 1.95 for iterations one through four, i.e., no more than four iterations are required to achieve convergence. It is noteworthy that $\alpha_{a}=1.95$ is consistent with the values of 1.8 to 1.9 and 2 reported by Schnaiter et al. (2005) and Kirchstetter et al. (2004) for biomass burning particles, respectively. For comparison, using $m_{s}=0$ as suggested by W2003 $\left(m_{s}=0\right)$ yields average $\alpha_{a}$ values of about 1.5. Hence, this can be interpreted as support for the $m_{s}$ factors provided by A2005. We note that the values near 1.5 that were also reported by Schnaiter et al. (2005) are not considered relevant here, since they correspond to particle size distributions with unrealistically large count median diameters $(\sim 350 \mathrm{~nm}$; here: $\mathrm{CMD}<200 \mathrm{~nm}$ (Rissler et al., 2006)). Additional laboratory calibrations should be performed to resolve the apparent discrepancies in the $m_{s}$ calibration factors. In the following we will utilize the calibration factors by A2005 to 
estimate the spectral dependence of $C$ (see Table 1).

With $\alpha_{a}=1.95$ we find from Eq. (24) that $A=-0.1178$ and $B=1.982$ and with Eq. (23) we can write

$C_{\lambda}=C_{532} \frac{\lambda^{-0.1178 \ln (\lambda / \mathrm{nm})+1.982}}{532 \mathrm{~nm}^{-0.1178 \ln (532)+1.982}}$,

i.e., $C_{450}=4.79, C_{590}=5.50, C_{615}=5.61, C_{660}=5.80, C_{880}$ $=6.54$ and $C_{950}=6.73$. Hence, for the five Aethalometer channels between 450 to $660 \mathrm{~nm}, C_{\lambda}$ increases by $10.9,15.9$ and $21.6 \%$ for $\alpha_{a}=1.0,1.5$ and 2.0, respectively. Consequently, for the SMOCC campaign with $\lambda_{\text {ref }}=532 \mathrm{~nm}$, assuming a $\lambda$-independent $C\left(=C_{532}\right)$ value for the Aethalometer channels between 450 and $660 \mathrm{~nm}$ introduces an error in $\sigma_{\text {aeth }}$ of less than $\pm 5.5, \pm 7.9$ and $\pm 11.2 \%$ for $\alpha_{a}=1.0,1.5$ and 2.0, respectively. For the worst case $(950 \mathrm{~nm}), C$ is expected to be $9.0,19.0$ and $31.5 \%$ larger than $C_{532}$ for $\alpha_{a}=1$, 1.5 and 2, respectively, i.e., except for possibly $\alpha_{a}=1.0$, the wavelength dependence of $C$ can not be neglected. This seems to be in contradiction to W2003 who concluded from the small (up to $10 \%$ ) increase in $C_{\lambda}$ from 450 to $660 \mathrm{~nm}$ for soot particles (with $\alpha_{a} \sim 1.0$ ), that the spectral dependence of $C$ is negligible. As seen from Table 1 their measurements are consistent with A2005 (10.9\% increase in $C$ for this case), but their conclusion is limited to the spectral range between 450 and $660 \mathrm{~nm}$ as discussed above.

In summary, we argue that for the SMOCC data $f$ is equal to 1.2 independent of wavelength, while $C$ depends on wavelength and, consequently, the best Aethalometer accuracy is obtained, if $C_{\lambda}$ is calculated from Eq. (28). On the other hand, assuming $C$ to be independent of wavelength $\left(C_{\lambda} \cong C_{532}\right)$ for the five AE30 channels between 450 and $660 \mathrm{~nm}$ does not introduce systematic errors larger than $\pm 11 \%$, a bias that is much smaller than the calibration uncertainty ( $\sim 20 \%$; see Sect. 3.2.5). However, for the $850 \mathrm{~nm}$ and $950 \mathrm{~nm}$ channels Eq. (28) should be used. This restriction can be relaxed for sample aerosol with $\alpha_{a} \cong 1.0$, where $C_{\lambda} \cong C_{532}$ does not introduce biases larger than $9 \%$.

\subsubsection{Dependence on sampling period}

Since the Aethalometer response is known to depend on aerosol properties and hence on sampling location (Petzold et al., 1997; Arnott et al., 2005), it is conceivable that the correction factors $C$ and $f$ varied with pollution level and sampling period. Using $C_{532}=5.23$ and $f=1.20$, Figs. $8 \mathrm{a}$ and b show the ratio of $\sigma_{\text {aeth }}($ at $532 \mathrm{~nm})$ and $\sigma_{\text {PAS }}$ as a function of the pollution level (indicated by $\sigma_{\mathrm{PAS}}$ ) for both the dry and transition period of the SMOCC campaign, respectively, where the seasonal mean values of 0.943 and 1.034, respectively, are indicated by horizontal lines. While there is no systematic dependence of $\sigma_{\text {ath }} / \sigma_{\mathrm{PAS}}$ on $\sigma_{\mathrm{PAS}}$ for the transition period, there is a small negative trend for the dry period, which will result in a $13 \%$ difference in slopes derived from the linear regression of $\sigma_{\text {aeth }}$ and $\sigma_{\text {PAS }}$ (data not shown) given by $\sigma_{\text {aeth }}=0.87 \sigma_{\mathrm{PAS}}\left(\mathrm{Mm}^{-1}\right)+0.98 \mathrm{Mm}^{-1}\left(\mathrm{R}^{2}=0.91\right)$
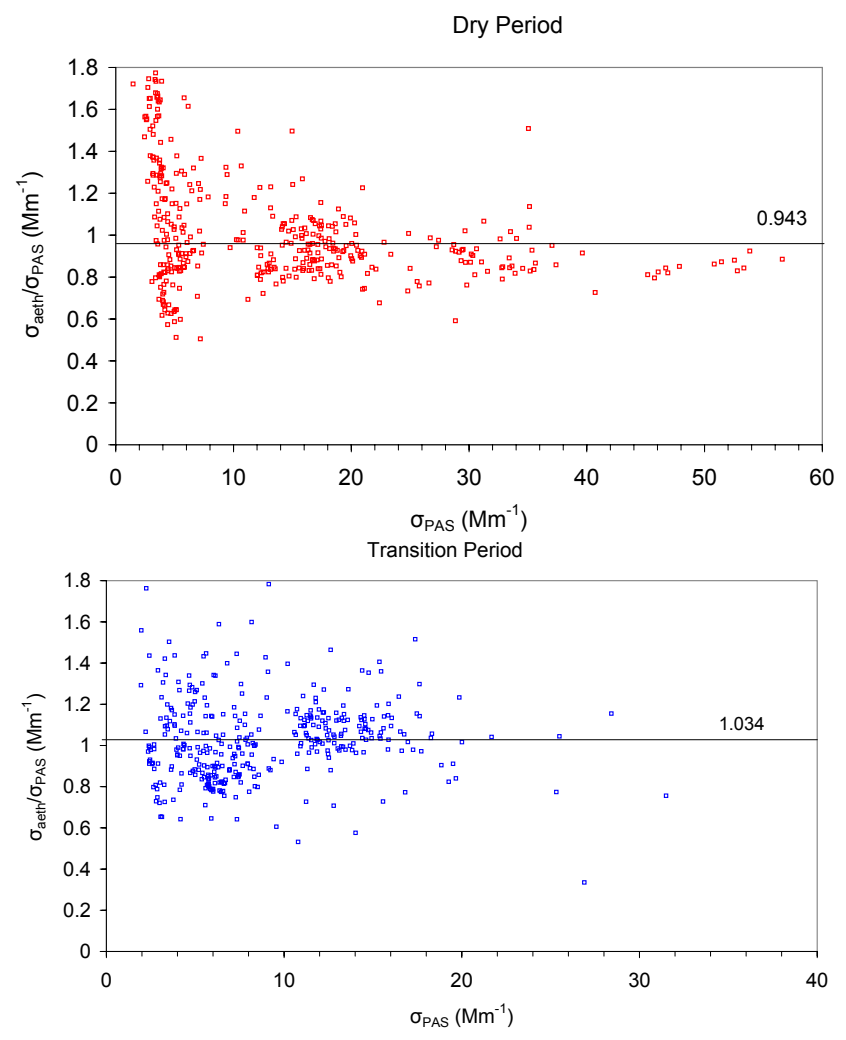

Fig. 8. Dependence of the normalized corrected Aethalometer data on pollution level (represented by $\sigma_{\text {PAS }}$ ) and sampling period, namely the dry (a) and transition period (b).

and $\sigma_{\text {aeth }}=1.00 \sigma_{\text {PAS }}\left(\mathrm{Mm}^{-1}\right)+0.49 \mathrm{Mm}^{-1}\left(\mathrm{R}^{2}=0.73\right)$ for the dry and transition period, respectively. The larger slope (and arithmetic mean of $\left.\sigma_{\text {aeth }} / \sigma_{\mathrm{PAS}}\right)$ for the transition period is consistent with the previously discussed enhanced aerosol mass bias $(8 \%$ and $15 \%$ for the dry and transition period, respectively) induced by the difference in inlet cut-off diameters $(10 \mu \mathrm{m}$ versus $1.5 \mu \mathrm{m})$. However, despite these small differences we conclude that there is no systematically significant dependence of the Aethalometer correction factors on sampling period. Thus, unless stated otherwise, we will henceforth not distinguish between dry and transition period.

For the wet season, it was impossible to calibrate the Aethalometer and PSAP, mainly due to the poor signal-tonoise ratio and the unavoidable small drifts in zero offset of the PAS. Hence, for lack of a better alternative, we recommend to apply the correction factors derived for the dry and transition period also to the Aethalometer and PSAP data of the wet period.

\subsubsection{Dependence on relative humidity}

As mentioned above, while the PAS was operated under dry conditions $(R H<45 \%)$, the sample air supplied to the Aethalometer was not actively dried, i.e., it closely 


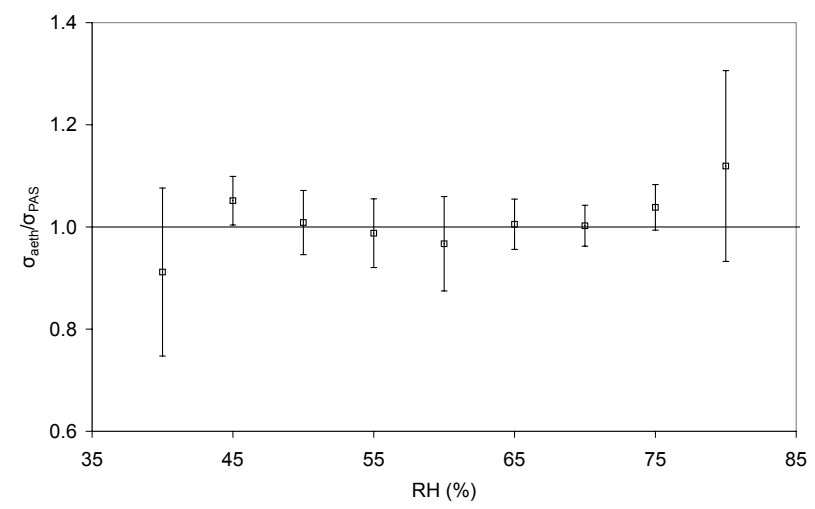

Fig. 9. The effect of relative humidity $(R H)$ on Aethalometer performance. Depicted are the mean and $95 \%$ confidence level of the ratios of ambient and dry absorption coefficients as measured by the Aethalometer $\left(\sigma_{\text {aeth }}\right)$ and the photoacoustic spectrometer $\left(\sigma_{\mathrm{PAS}}\right)$, respectively.

approximated ambient conditions. Figure 9 depicts the Aethalometer-based ambient absorption coefficient $\left(\sigma_{\text {aeth }}\right)$ normalized to dry absorption ( $\left.\sigma_{\mathrm{PAS}}\right)$ as a function of $R H$. For each $R H$ segment, the mean and $95 \%$ confidence level of the mean was calculated. It is evident that there is no statistically significant dependence of $\sigma_{\text {aeth }}$ on $R H$ at least for $R H$ between 40 and $80 \%$.

\subsubsection{Dependence on single scattering albedo $\omega_{0}$}

The effect of $\omega_{0}$ on the Aethalometer signal can be assessed based on Eq. (17). Laboratory studies by W2003 and A2005 reported $m_{s}$ values of $\sim 0.008$ and 0.055 (at $550 \mathrm{~nm}$ ), respectively, for purely scattering aerosol (i.e., up to $5.5 \%$ of aerosol light scattering is erroneously interpreted as absorption). During the dry and transition period of the SMOCC campaign, $\omega_{0}$ was approximately constant at $0.92 \pm 0.02$ (Chand et al., 2006). Using Eq. (17) with $m_{s}=0.055$ as an estimated upper limit of the aerosol scattering effect, we can attribute up to $13.0 \pm 3.5 \%$ of the observed multiple scattering correction $C_{532}(=5.23)$ to aerosol light scattering, i.e., the multiple scattering factor corrected for aerosol scattering is given by $C_{532}^{*}=4.55$. Hence, compared to multiple scattering within the filter matrix $\left(C_{532}^{*}=4.55\right)$ the effect due to the scattering properties of the aerosol is relatively small. While for urban pollution, this effect can be expected to be even smaller (smaller $\omega_{0}$ ), the scattering contribution for desert dust and (maritime) background is likely to be larger. Using $\omega_{0,550}=0.965$ as a typical average value for background air and desert dust (Dubovik et al., 2002). $C_{532}^{*}$ would have to be increased by about $40 \%$ to account for aerosol scattering effects, i.e. $C_{532} \sim 6.4$.

Finally, we note that, since the small variability in $\omega_{0}$ $( \pm 0.02)$ during SMOCC translates into a relatively small effect on $C_{532}(3.5 \%)$, it would have been impossible to distinguish the aerosol scattering $\left(m_{s}\right)$ from the multiple scattering effect of the filter substrate, i.e., it is impossible to derive a value for $m_{s}$ from the SMOCC data.

\subsubsection{Gaseous adsorption onto the filter}

Gaseous adsorption onto quartz filters is a well-known phenomenon that potentially enhances the multiple scattering effect of the filter, and hence introduces a positive bias in $C$ (Kirchstetter et al., 2001). To our knowledge, there has been no previous study of this phenomenon for either the PSAP or the Aethalometer.

The intuitive approach for an investigation of this effect is to look for systematically enhanced $C$ values for large pollution levels. However, since each Aethalometer measurement cycle begins with an acclimatization phase, which exposes the (initially) clean filter spot to ambient air without taking data, and references the measured attenuation to the zero value obtained during this acclimatization phase, a potential dependence of $C$ on pollution level is eliminated. This explains why we found no statistically significant dependence of $C_{532}$ on sampling period despite the substantially higher pollution levels during the dry period with an average $\sigma_{a}$ $(550 \mathrm{~nm})$ of 22.9 and $7.5 \mathrm{Mm}^{-1}$ for the dry and transition period, respectively (see Fig. 8).

However, if gaseous adsorption introduces a bias into $C$ it can be detected according to the following rationale. Let us assume that at time $t_{0}$ the filter is in equilibrium with the gas phase, i.e., there is no net transport of gas molecules to or from the filter. If the pollution level changes at time $t_{1}$, there will be a net transport of gas molecules to or from the filter depending on whether the pollution level increases or decreases, respectively. Furthermore, if gaseous adsorption is present and has an effect on $C$ and if the relaxation time for adsorption/desorption is smaller than the averaging time of the Aethalometer (here $15 \mathrm{~min}$ ) one would expect a systematic dependence of the relative gradient of $C$ on the gradient in pollution level. Expressing the gradient of $C$ (here $\left.C_{532}\right)$ at time layer i as

$$
\frac{\Delta C}{C}=\frac{C^{i+1}-C^{i}}{\left(C^{i+1}+C^{i}\right) / 2}
$$

and using the gradient in $\mathrm{CO}$ as proxy for changes in pollution level

$$
\frac{\Delta \mathrm{CO}}{\mathrm{CO}}=\frac{\mathrm{CO}^{i+1}-\mathrm{CO}^{i}}{\left(\mathrm{CO}^{i+1}+\mathrm{CO}^{i}\right) / 2}
$$

we found no correlation $\left(R^{2}<0.1\right)$ between the relative gradients in $C$ and $\mathrm{CO}$. The same result was found, if $\mathrm{NO}_{2}$ instead of $\mathrm{CO}$ was used as proxy for the pollution level. Performing this analysis also for the PSAP yielded the same result $\left(R^{2}<0.04\right)$. It is important to note that we do not suggest that $\mathrm{NO}_{2}$ or $\mathrm{CO}$ actually adsorb to the filter; these components only serve as a proxy for pollution events driven by photochemistry and/or biomass burning. Although we can 
not rule out the possibility that there are adsorbing gaseous components that do not correlate well with $\mathrm{CO}$ or $\mathrm{NO}_{2}$, this analysis suggests that neither the Aethalometer nor the PSAP suffer from significant measurement artifacts due to adsorption of gaseous components.

\subsubsection{Accuracy}

The accuracy of $\sigma_{\text {aeth }}$ is determined by the accuracy of $C$. As mentioned above, for wavelengths between 450 and $660 \mathrm{~nm}$, $C_{\lambda}$ can be approximated by $C_{532}$ with an estimate accuracy and precision (95\% confidence level) of about $20 \%$ and $30 \%$ (15-min averages), respectively, except for the $571 \mathrm{~nm}$ channel, which was systematically too low. For wavelengths larger than $660 \mathrm{~nm}$ (here 880 and $950 \mathrm{~nm}$ ), this level of accuracy can only be maintained, if $C_{532}$ is converted into $C_{\lambda}$ using Eq. (28). The Aethalometer accuracy is lower than the PSAP accuracy to account for additional uncertainties due to wavelength conversion (uncertainties in $\alpha_{a}$ ) and the use of different inlets.

\section{Discussion}

\subsection{PSAP}

The PSAP was used in numerous field studies (Reid et al., 1998; Anderson et al., 1999; Mader et al., 2002; Wex et al., 2002; Arnott et al., 2003; Guyon et al., 2003a, b). Most of these studies accounted for instrument artifacts due to flow rate, spot size and aerosol scattering using the calibration factors by B1999. For Amazonian aerosol, we found that the Bond correction did not account for a bias that scaled well with $R H$ and $\mathrm{T}$ (see Figs. 5a and b). As seen in Fig. 5c this bias can be accounted for by using a $R H$ dependent correction factor (see Eq. 27). In this section we compare these findings to other PSAP calibration studies.

V2005a has essentially confirmed the Bond correction for external mixtures of kerosene soot and ammonium sulfate particles. However, the observed deviations for pure soot (from a kerosene lamp) and for purely scattering particles resulted in the derivation of a new ( $\omega_{0}$ dependent) loading correction. Since the Bond calibration was performed with spherical particles (internal mixtures of nigrosin and ammonium sulfate), inconsistencies for fractal-like soot agglomerates as described by V2005a are conceivable. Unfortunately, V2005a was unable to derive a "unified" correction scheme that would be applicable to all types of aerosols used (ammonium sulfate, PSL, soot, and external mixtures thereof). During the $\sim 1.5$ day period of their outdoor experiment in Reno, NV, V2005a reported PSAP absorption coefficients that were by $16 \%$ and $22 \%$ higher than the reference absorption at $530 \mathrm{~nm}$ where using their own correction scheme $(1-\lambda$ PSAP correction parameters) and the Bond correction, respectively. This compares well with the $+18 \%$ bias of $\sigma_{\mathrm{PSAP} \text {, Bond re- }}$ ported in this study for $R H>30 \%$ (Fig. 5a). To our know- ledge, there are only two more PSAP field calibrations with a true in-situ reference method such as the difference method or the PAS. The study by Reid et al. (1998) did not account for PSAP artifacts, since it was performed prior to B1999 and Arnott et al. (2003) found that $\sigma_{\mathrm{PSAP}, \mathrm{B} o n d}$ was by a factor of 1.61 larger than $\sigma_{\mathrm{PAS}}(532 \mathrm{~nm})$ for rural aerosols from the North Central Oklahoma.

None of the previous PSAP calibrations reports a systematic dependence of the PSAP performance on $R H$ and/or T. On the other hand, there is evidence for a $R H$ sensitivity of the PSAP. For instance, Arnott et al. (2003) reported an erratic response of the PSAP for rapidly changing $R H$ (also seen by us) and Guyon et al. (2004) had to discard PSAP data, if $R H$ exceeded $92 \%$. Changes in $R H$ may affect the amount of water that condenses into the cavities of the filter matrix. As a consequence the optical properties of the filter may change and hence filter-based absorption techniques may depend on $R H$. In addition, hygroscopic aerosol growth may "truly" enhance aerosol light absorption due to the optical interaction between aerosol core and coating (Fuller et al., 1999), but for ambient aerosol absorption enhancement factors larger than about 1.1 are difficult to justify at least for $R H<80 \%$ (Redemann et al., 2001). As seen from Figs. 5a and $\mathrm{b}$ the normalized PSAP response $\left(\sigma_{\mathrm{PSAP}, \mathrm{Bond}} / \sigma_{\mathrm{PAS}}\right)$ increased by a factor of 2 for an increase in $R H$ from 20 to $30 \%$ and/or an increase in $\mathrm{T}$ from 24 to $26^{\circ} \mathrm{C}$, respectively. Hence, we conclude that the observed bias is an instrument artifact of either the PSAP or the PAS. As mentioned above, there is both theoretical and experimental evidence for the absence of an $R H$ sensitivity of the PAS for $R H<80 \%$ (Raspet et al., 2001; Arnott et al., 2003) and the moderate dependence of the PAS signal on $\mathrm{T}$ is accounted for by repeated acoustic calibrations (every $10 \mathrm{~min}$ ) as described above. In addition, comparison of the Aethalometer and the PAS has not shown any $R H$ or $\mathrm{T}$ dependent bias. Hence, we attribute the observed bias of $\sigma_{\mathrm{PSAP}, \mathrm{Bond}} / \sigma_{\mathrm{PAS}}$ to a systematic error of the PSAP.

As mentioned above both $R H$ and $\mathrm{T}$ displayed a pronounced diel variation such that most of the low $R H$ and $\mathrm{T}$ values were encountered during nighttime sampling. The resulting correlation of $R H$ and T makes it impossible to conclusively decide whether the observed PSAP bias is due to $R H$ or $\mathrm{T}$ or both. The significant scatter in both Figs. 5a and $\mathrm{b}$ suggests that there is possibly a sensitivity of the PSAP to both $R H$ and T or may be even to another - as yet unidentified - parameter. As mentioned above $\sigma_{\mathrm{PSAP}, \text { Bond }} / \sigma_{\mathrm{PAS}}$ did not show any correlation with filter loading (for transmittance $>0.5$, i.e., ATN $<70$ ) or single scattering albedo (for $0.85<\omega_{0,550}<0.95$ ). Furthermore, laboratory measurements indicate that $\sigma_{\mathrm{PSAP}, \text { Bond }}$ does not depend on $\sigma_{\mathrm{PAS}}$ or $\sigma_{s}$ (V2005a). To our knowledge a potential PSAP sensitivity to $R H$ and $\mathrm{T}$ has not been systematically investigated yet. If $R H$ is the culprit, the drastic change near $R H=20 \%$ may be a result of a wettability threshold of the PSAP filter near $R H=20 \%$. On the other hand, it is also conceivable that there 
is a temperature sensitivity of the PSAP electronics and/or optics that results in the observed drift of the PSAP. This issue should be explored further in a laboratory study under controlled $R H$ and $\mathrm{T}$ conditions. For the purposes of this study, it is sufficient to adjust the Bond-corrected PSAP data with the factor $K_{R H}$ (Eq. 27). The resulting PSAP-derived absorption coefficient $\left(\sigma_{\mathrm{PSAP}}\right)$ showed excellent agreement $(<6 \%)$ and correlation $\left(\mathrm{R}^{2}=0.954\right)$ with the reference absorption coefficient ( $\left.\sigma_{\mathrm{PAS}}\right)$ (see Fig. 5c).

In summary, we conclude that the Bond correction is generally quite adequate for most ambient aerosols $(\sim 25 \%$ accuracy) with three possible exceptions: (1) purely fractal-like agglomerates, (2) purely scattering particles (i.e., $\omega_{0}$ close to unity) and (3) varying $R H$ and/or T conditions (for $R H<30 \%$ and $\mathrm{T}<25^{\circ} \mathrm{C}$; see Figs. 5a and b). In this study nighttime PSAP data had to be corrected by a $R H$-dependent correction factor.

\subsection{Aethalometer}

For Amazonian aerosol, the Aethalometer calibration revealed a multiple scattering correction factor of $C_{532}=5.23 \pm 1.04$ (or $C_{532}^{*}=4.55 \pm 0.91$, if corrected for aerosol scattering effects according to A2005, i.e., $13 \%$ of $C_{532}$ can be attributed to aerosol scattering effects) and a much less significant bias due to filter loading $(0.76<R \leq 1$ at $532 \mathrm{~nm}$ ). Previous calibration studies reported $C$ values clustering around 2 or 4 depending on the type of challenge aerosol (W2003, A2005). For pure candle light soot particles and external mixtures of soot and ammonium sulfate, A2005 found $C^{*}$ values between 1.8 and 2.2 (depending on wavelength). On the other hand, they reported $C_{521}^{*}=3.7$ for ambient (urban) aerosols. Similarly, the laboratory study by W2003 found $C_{532}^{*}=2.14$ (here $C=C^{*}$, since, in contrast to A2005, W2003 considered the dependence of the Aethalometer performance on aerosol light scattering as negligible) for both pure soot (Diesel and PALAS) and external soot mixtures with ammonium sulfate (independent of wavelength). On the other hand, for soot (Diesel and PALAS) particles coated with organic carbon (internally mixed aerosol) their $C^{*}$ value increased to 3.6 which is very similar to 3.7 and $4.55 \pm 0.91$ as reported for ambient aerosol by A2005 and by the present study, respectively. We remind the reader that the value of 4.55 can be considered an upper limit due to the (unaccounted) positive bias (estimated as $<8$ and $15 \%$ for the dry and transition period, respectively) resulting from the larger cut-off diameter of the Aethalometer inlet.

Both A2005 and W2003 offered possible explanations for the factor of $\sim 2$ difference in $C^{*}$. A2005 hypothesized that variable particle preloading of the filter during the automatically performed filter acclimatization phase prior to any measurement might be responsible for the enhanced $C^{*}$ value under ambient conditions. However, in light of a maximum loading correction of no more than $30 \%(\sim 550 \mathrm{~nm})$, as was consistently reported by W2003, A2005 and the present study, a factor of 2 difference in $C^{*}$ seems hard to justify. On the other hand, W2003 speculated that adsorption of semi-volatile organic gaseous components onto the filter matrix might have artificially enhanced the multiple scattering within the filter matrix. However, as shown in Sect. 3.2.4, we found no indication for gaseous adsorption effects during the SMOCC campaign.

Although we are unable to resolve this issue conclusively, we offer a different explanation for the observed difference in $C^{*}$. The significance of the aerosol mixing state for light absorption is well known from Mie theory for coated particles (Bohren and Huffman, 1983). Petzold et al. (1997) argued that, for internal mixtures of black carbon (BC) and some mainly scattering material, the Aethalometer response may be enhanced by up to about a factor of 2 (for BC contents of about 3\%) compared to external mixtures (as was the case for the laboratory calibrations by W2003 and A2005). Hence, we suggest that the observed difference in $C^{*}$ may possibly be a result of attenuation enhancement due to internal mixing. This notion is corroborated by the fact that the Bond correction of the PSAP, that demonstrates good applicability to ambient aerosol, was performed with internal mixtures of nigrosin and ammonium sulfate (V2005a).

In summary, we suggest that in absence of an on-site calibration standard, $C_{532}^{*}$ values of 2.1 and 4.0 (average of 3.7, 3.6 and 4.55) should be used for pure or external mixtures of soot and internal mixtures of soot, respectively. The additional bias due to aerosol scattering can be taken into account by using Eq. (20) with the $m_{s}$ factors provided by A2005 (see Table 1). For particles with small absorption Ångström exponents $\left(\alpha_{a} \cong 1\right), C_{\lambda}$ can be approximated by $C_{532}(<10 \%)$. For $\alpha_{a}$ values up to 2 (as found during SMOCC), we found that $C_{\lambda}$ can be approximated by $C_{532}(<11 \%)$ for the five AE30 channels between 450 and $660 \mathrm{~nm}$. However, for the 880 and $950 \mathrm{~nm}$ channel, the spectral dependence of $C$ should be accounted for by using Eq. (23). Since the fit coefficients of Eq. (23) depend on $\omega_{0}$ and $\alpha_{s}$, these coefficients are aerosol-specific and therefore they should be calculated for the aerosol under consideration as described here for the SMOCC data $\left(\omega_{0,550}=0.92, \alpha_{s}=2\right)$.

The filter loading correction factor $R$ depends on attenuation and hence on $\lambda$. At the highest loading prior to the automatic filter change (ATN $=100,75$ and 40 for 450,532 and $950 \mathrm{~nm}) R$ is $0.76,0.8$ and 0.85 for $\lambda=450,532$, and $950 \mathrm{~nm}$, respectively, i.e., the measured attenuation coefficient on a pristine filter is 32,25 , and $18 \%$ larger than on a fully loaded filter, respectively. This is consistent with the values reported by W2003, i.e., in contrast to $C, R$ (and hence $f$ ) does not seem to depend on the mixing state of the sample aerosol. Furthermore, W2003 showed that the shadowing factor $f$ (see Eq. 11) is related to $\omega_{0}$ by $f=A(1-$ $\left.\omega_{0}\right)+1$, where $A=0.86 \pm 0.1$. Using $\omega_{0}=0.92$ (observed during SMOCC) yields $f=1.07 \pm 0.01$. Although this value is somewhat lower than experimentally determined value of 1.2 , it 
results in a less than $10 \%$ bias in $\sigma_{\text {aeth }}$, if we average over an entire filter cycle. W2003 acknowledged that the reliability of $A$ is limited due to significant scatter in the data and the validity of $A$ is possibly limited to "dark" aerosol, since most of their measurements were performed for $\omega_{0}<0.6$ and the few data points with $\omega_{0}>0.6$ have large error margins. Hence the apparent inconsistency between $f$ and $\omega_{0}$ is not surprising especially, if we also consider that $f$ not only depends on $\omega_{0}$ but on how deep the aerosol is embedded into the filter matrix (A2005), which may depend on particle size and morphology as well as on sampling flow rate.

In contrast to the PSAP, the Aethalometer shows no dependence on $R H$ (or $\mathrm{T}$ ) within the experimental uncertainty at least for $R H$ between 40 and $80 \%$ (Fig. 9). Similar to artifacts due to gaseous adsorption, $R H$ related Aethalometer artifacts should be at least partially accounted for by the filter acclimatization phase. Thus, one might conclude from Fig. 9 that there is no hygroscopic absorption enhancement. This is consistent with the previously mentioned theoretical predictions of Redemann et al. (2001), who estimated the hygroscopic absorption enhancement factor at $\lambda=550 \mathrm{~nm}$ as $\sim 1.1$ at $R H=80 \%$ for sulphuric acid coated soot particles with a realistic lognormal size distribution (geometric mean diameter and standard deviation of $0.12 \mu \mathrm{m}$ and 1.5 , respectively). In light of the small hygroscopic diameter growth factor of less than $1.08(R H=80 \%)$ for Amazonian aerosols (Rissler et al., 2006), we consider this absorption enhancement factor (1.1) to be an upper limit for our study. However, we add as an important caveat that the Aethalometer may not be capable at all of accurately measuring the electromagnetic focusing effect of absorbing particles enclosed by a liquid coating, since the shape (and hence the optical properties) of the partially liquid particle is expected to change upon deposition onto a filter substrate.

Finally, in Figs. 10a and $\mathrm{b}$ we compare $1 \mathrm{~h}$ averages of PSAP and Aethalometer (adjusted to $532 \mathrm{~nm}$ ) data for the dry and transition period, respectively. It is evident that the instruments are well correlated for both periods (dry: $R^{2}=0.88$; transition: $R^{2}=0.90$ ) and, forcing the linear regression line through the origin, $\sigma_{\mathrm{PSAP}}$ is by about $9.8 \%$ larger (slope $=$ $1.098 \pm 0.047$ ) and $2.5 \%$ smaller (slope $=0.975 \pm 0.030$ ) than $\sigma_{\text {aeth }}$ for the dry and transition period, respectively. Considering that Fig. 10 represents more than 2 months of data, while the calibration of the PAS and PSAP was based on only $200 \mathrm{~h}$, the agreement of the instruments is quite satisfactory and the slopes agree within the estimated instrument accuracies. On the other hand, the correlation is weaker for $\sigma_{a}>40 \mathrm{Mm}^{-1}$. We attribute this to the scarcity of PAS data for this absorption range as seen from Figs. $5 \mathrm{c}$ and 8. Hence, we add as a caveat that the reliability of the PSAP and Aethalometer calibration is somewhat weaker for $\sigma_{a}>40 \mathrm{Mm}^{-1}$, although even in this range the agreement between PSAP and Aethalometer is better than 25\%, the estimated $2 \sigma$ level based on the instrument accuracies.

\section{Conclusions}

A 1- $\lambda$ PSAP (Particle Soot Absorption Photometer, $565 \mathrm{~nm}$ ) and a $7-\lambda$ AE30 Aethalometer (450-950 nm) were compared to a PAS (photoacoustic spectrometer, $532 \mathrm{~nm}$ ) based on $200 \mathrm{~h}$ of collocated ambient sampling at a rural site in the Amazon Basin during the dry and wet-to-dry transition period of the LBA-SMOCC campaign in 2002. The data are heavily influenced by biomass burning events. To ensure data quality we verified the PAS accuracy of $10 \%$ in the field following the calibration procedure described by Arnott et al. (2000) using $\mathrm{NO}_{2}$ as calibration gas.

The calibration of the PSAP with the PAS essentially confirmed the Bond correction (B1999), except for a previously not reported bias that correlated well with $R H$ and/or $\mathrm{T}$ for low $R H$ (20 to $30 \%$ ) and $\mathrm{T}$ values $\left(24\right.$ to $26^{\circ} \mathrm{C}$ ). Although the data presented here does not provide conclusive evidence that the PSAP is sensitive to $R H$ and/or T, we were able to account for an observed systematic bias in the PSAP data using a $R H$ dependent correction factor. The manufacturer-provided loading correction was found adequate for transmissions down to $0.5(\mathrm{ATN}<70)$. For the limited range of single scattering albedos encountered here $\left(0.85<\omega_{0,550}<0.95\right)$, no $\omega_{0}$ sensitivity was observed. Based on field calibrations we estimated the accuracy (95\% confidence level) of the Bondcorrected PSAP data as about $25 \%$. With the additional onsite PAS calibration, the value improved to about $15 \%$.

For Amazonian haze particles, the multiple scattering correction factor of the Aethalometer at the reference wavelength of $532 \mathrm{~nm}$ was $C_{532}=5.23 \pm 1.05$ or, if aerosol scattering effects are subtracted, $C_{532}^{*}=4.55 \pm 0.91$. The loading correction $(0.7<R<1)$ was adequately described by Eq. (11) using a shadowing factor of $f=1.2$. Based on the limited available information in the literature, we argued that the shadowing factor $f=1.20$ is independent of wavelength (bias $<10 \%$ ) and the wavelength dependence of $C$ can be parameterized using the data by A2005, if the single scattering albedo $\omega_{0}$ (at a reference wavelength) and the scattering Ångström exponent $\alpha_{s}$ are known (Eqs. 23 and 24). This parameterization showed that $C_{\lambda}$ can be approximated by $C_{532}$ to better than $11 \%$, if either the absorption Ångström exponent $\alpha_{a}$ is close to unity (i.e. soot-dominated aerosol) or the spectral range is limited to between 450 to $660 \mathrm{~nm}$. For the Amazoninan haze aerosol with $\alpha_{a}$ near $1.95, C_{\lambda}$ was calculated for each of the seven Aethalometer channels based on Eqs. (23) and (24). Not accounting for the spectral dependence of $C$ would lead to a positive bias of about $30 \%$ in the $950 \mathrm{~nm}$ channel and a substantially reduced $\alpha_{a}$ value of about 1.5 . We also note that, for unknown reasons, the $571 \mathrm{~nm}$ channel of the AE30 Aethalometer was consistently by about $20 \%$ too low. For all other channels, the $(2 \sigma)$ accuracy was estimated as $20 \%$.

We found no sensitivity of the PSAP and Aethalometer to gaseous adsorption onto the filter matrix. In addition, except for the aforementioned instrument artifact of the PSAP that correlated well with $R H$ (and T), we found 

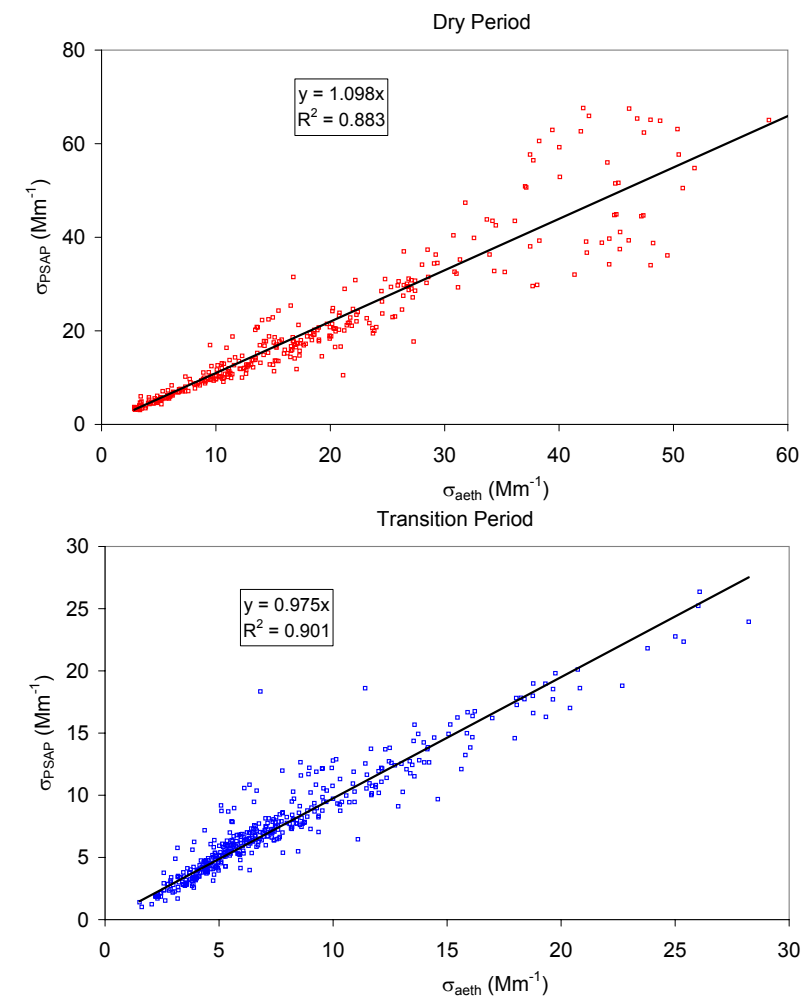

Fig. 10. Comparison of the absorption coefficients (at 532) measured by PSAP and Aethalometer for both the dry (a) and transition period (b).

also no dependence of aerosol absorption $\left(\sigma_{a}\right)$ on $R H$. While the absence of an hygroscopic absorption enhancement for $R H \leq 80 \%$ is consistent with theoretical predictions (Redemann et al., 2001), it is questionable whether humidified particles deposited onto a filter substrate display the same optical properties as in the suspended state.

This study shows that, while laboratory calibration experiments are useful, on-site calibrations of the PSAP and Aethalometer are required for ambient measurements to ensure data quality. Although both PSAP and Aethalometer are based on the integrating-plate method, the conversion of the measured attenuation $\left(\sigma_{\mathrm{ATN}}\right)$ into absorption $\left(\sigma_{a}\right)$ requires different correction parameters due to the different filter types used. If an on-site calibration cannot be provided, we offer the following suggestions for retrieving absorption coefficients from PSAP or Aethalometer data:

1) For the 1- $\lambda$ PSAP, the Bond correction (Eq. 25) can be applied with an expected uncertainty of about $25 \%(2 \sigma)$ and $R H$ and $\mathrm{T}$ should be kept constant to avoid potential $R H$ and $\mathrm{T}$ induced biases.

2) For the 7- $\lambda$ Aethalometer, the situation is more complicated. We suggest a multiple scattering correction factor $C_{532}^{*}$ of either 2.1 for pure and externally mixed soot (e.g., near a combustion source) or 4.0 for internally mixed aerosol (e.g., for aged ambient aerosol). If concomitant measurements of spectrally resolved aerosol scattering are available, Eq. (20) can be used to determine $C_{532}$. Otherwise, the additional bias due to aerosol scattering can be approximately accounted for by increasing the $C_{532}^{*}$ values by $10 \%$ for non-background air $\left(10 \%\right.$ corresponds to $\left.\omega_{0,550} \sim 0.90\right)$ to yield $C_{532}$ values of 2.3 and 4.4 for externally and internally mixed aerosol, respectively. For background and desert dust regions an increase of about $40 \%$ (corresponds to $\omega_{0,550} \sim 0.965$ ), i.e., $C_{532}$ values of 2.9 or 5.6 , may be more realistic. If the absorbing component of the sample aerosol is mainly due to soot from internal combustion engines, $\alpha_{a}$ is close to 1 (Kirchstetter et al., 2004), i.e., $C_{\lambda} \cong C_{532}$ ( $<11 \%$ bias) for $450 \mathrm{~nm}<\lambda<950 \mathrm{~nm}$. On the other hand, if the absorbing aerosol component mainly results from biomass combustion, $\alpha_{a}$ is closer to 2 (Kirchstetter et al., 2004) and at least $C_{880}$ and $C_{950}$ should be calculated from Eq. (28). The loading correction $R$ is given by Eq. (11) with $f=1.2$ for $\omega_{0,532} \sim 0.9$ and for $\omega_{0,532}$ smaller than about $0.85, f$ can be estimated from $f=0.86\left(1-\omega_{0,532}\right)+1$ as recommended by W2003. Now Eq. (9) can be used to yield absorption coefficients with an estimated $(2 \sigma)$ accuracy of about $25 \%$.

Acknowledgements. This work was carried out within the frame work of the Smoke, Aerosols, Clouds, Rainfall, and Climate (SMOCC) project, a European contribution to the Large-Scale Biosphere-Atmosphere Experiment in Amazonia (LBA). It was financially supported by the Environmental and Climate Program of the European Commission (contract No. EVK2-CT-2001-00110 SMOCC), the Max Planck Society (MPG), the Fundação de Amparo à Pesquisa do Estado de São Paulo, and the Conselho Nacional de Desenvolvimento Científico (Instituto do Milênio LBA). We thank all members of the LBA-SMOCC and LBA-RACCI Science Teams for their support during the field campaign, especially A. C. Ribeiro, M. A. L. Moura, and J. von Jouanne as well as P. Guyon for providing his Mie code and adapting it to our needs. Finally, we thank an anonymous referee for his/her careful review and helpful comments.

Edited by: D. Rosenfeld

\section{References}

Ackerman, A. S., Toon, O. B., Stevens, D. E., Heymsfield, A. J., Ramanathan, V., and Welton, E. J.: Reduction of tropical cloudiness by soot, Science, 288, 1042-1047, 2000.

Andreae, M. O., Artaxo, P., Brandão, C., Carswell, F. E., Ciccioli, P., da Costa, A. L., Culf, A. D., Esteves, J. L., Gash, J. H. C., Grace, J., Kabat, P., Lelieveld, J., Malhi, Y., Manzi, A. O., Meixner, F. X., Nobre, A. D., Nobre, C., Ruivo, M. D. L. P., Silva-Dias, M. A., Stefani, P., Valentini, R., von Jouanne, J., and Waterloo, M. J.: Biogeochemical cycling of carbon, water, energy, trace gases and aerosols in Amazonia: 
The LBA-EUSTACH experiments, J. Geophys. Res., 107, 8066, doi:10.1029/2001JD000524, 2002.

Andreae, M. O., Rosenfeld, D., Artaxo, P., Costa, A. A., Frank, G. P., Longo, K. M., and Silva-Dias, M. A. F.: Smoking rain clouds over the Amazon, Science, 303, 1337-1342, 2004.

Arnott, W. P., Hamasha, K., Moosmüller, H., Sheridan, P. J., and Ogren, J. A.: Towards aerosol light-absorption measurements with a 7-wavelength aethalometer: Evaluation with a photoacoustic instrument and 3-wavelength nephelometer, Aerosol Sci. Technol., 39, 17-29, 2005.

Arnott, W. P., Moosmüller, H., Rogers, C. F., Jin, T., and Bruch, R.: Photoacoustic spectrometer for measuring light absorption by aerosol: Instrument description, Atmos. Environ., 33, 28452852, 1999.

Arnott, W. P., Moosmüller, H., Sheridan, P. J., Ogren, J. A., Raspet, R., Slaton, W. V., Hand, J. L., Kreidenweis, S. M., and Collett, J. L.: Photoacoustic and filter-based ambient aerosol light absorption measurements: Instrument comparisons and the role of relative humidity, J. Geophys. Res., 108, 4034, doi:10.1029/2002JD002165, 2003.

Arnott, W. P., Moosmüller, H., and Walker, J. W.: Nitrogen dioxide and kerosene-flame soot calibration of photoacoustic instruments for measurement of light absorption by aerosols, Rev. Sci. Instrum., 71, 4545-4552, 2000.

Ballach, J., Hitzenberger, R., Schultz, E., and Jaeschke, W.: Development of an improved optical transmission technique for black carbon (BC) analysis, Atmos. Environ., 35, 2089-2100, 2001.

Bohren, C. F. and Huffman, D. R.: Absorption and scattering of light by small particles, Wiley, New York, USA, 1983.

Bond, T. C., Anderson, T. L., and Campbell, D.: Calibration and intercomparison of filter-based measurements of visible light absorption by aerosols, Aerosol Sci. Technol., 30, 582-600, 1999.

Chand, D., Guyon, P., Artaxo, P., Schmid, O., Frank, G. P., Rizzo, L. V., Mayol-Bracero, O. L., Gatti, L. V., and Andreae, M. O.: Optical and physical properties of aerosols in the boundary layer and free troposphere over the Amazon Basin during the biomass burning season, Atmos. Chem. Phys, 6, 2911-2925, 2006.

Dubovik, O., Holben, B., Eck, T. F., Smirnov, A., Kaufman, Y. J., King, M. D., Tanre, D., and Slutsker, I.: Variability of absorption and optical properties of key aerosol types observed in worldwide locations, J. Atmos. Sci. 59, 590-608, 2002

Fuller, K. A., Malm, W. C., and Kreidenweis, S. M.: Effects of mixing on extinction by carbonaceous particles, J. Geophys. Res.Atmos., 104, 15 941-15 954, 1999.

Gundel, L. A., Dod, R. L., Rosen, H., and Novakov, T.: The relationship between optical attenuation and black carbon concentration for ambient and source particles, Sci. Total Environ., 36, 197-202, 1984.

Guyon, P., Boucher, O., Graham, B., Beck, J., Mayol-Bracero, O. L., Roberts, G. C., Maenhaut, W., Artaxo, P., and Andreae, M. O.: Refractive index of aerosol particles over the Amazon tropical forest during LBA-EUSTACH 1999, J. Aerosol Sci., 34, 883907, 2003a.

Guyon, P., Graham, B., Beck, J., Boucher, O., Gerasopoulos, E., Mayol-Bracero, O. L., Roberts, G. C., Artaxo, P., and Andreae, M. O.: Physical properties and concentration of aerosol particles over the Amazon tropical forest during background and biomass burning conditions, Atmos. Che. Phys., 3, 951-967, 2003 b.

Guyon, P., Graham, B., Roberts, G. C., Mayol-Bracero, O. L.,
Maenhaut, W., Artaxo, P., and Andreae, M. O.: Sources of optically active aerosol particles over the Amazon forest, Atmos. Environ., 38, 1039-1051, 2004.

Hansen, A. D. A., Rosen, H., and Novakov, T.: The aethalometer - an instrument for the real-time measurement of optical absorption by aerosol particles, Sci. Total Environ., 36, 191-196, 1984.

Heintzenberg, J. and Charlson, R. J.: Design and applications of the integrating nephelometer: A review, American Meteorological Society, 13, 987-1000, 1996.

Horvath, H.: Atmospheric light-absorption - a review, Atmospheric Environment Part a - General Topics, 27, 293-317, 1993.

Kirchstetter, T. W., Corrigan, C. E., and Novakov, T.: Laboratory and field investigation of the adsorption of gaseous organic compounds onto quartz filters, Atmos. Environ., 35, 1663-1671, 2001.

Kirchstetter, T. W., Novakov, T., and Hobbs, P. V.: Evidence that the spectral dependence of light absorption by aerosols is affected by organic carbon, J. Geophys. Res.-Atmos., 109, 1208 , doi:10.1029/2004JD004999, 2004.

Kirkman, G. A., Gut, A., Ammann, C., Gatti, L. V., Cordova, A. M., Moura, M. A. L., Andreae, M. O., and Meixner, F. X.: Surface exchange of nitric oxide, nitrogen dioxide, and ozone at a cattle pasture in Rondonia, Brazil, J. Geophys. Res., 107, 8083, doi:10.1029/2001JD000523, 2002.

Kopp, C., Petzold, A., and Niessner, R.: Investigation of the specific attenuation cross-section of aerosols deposited on fiber filters with a polar photometer to determine black carbon, J. Aerosol Sci., 30, 1153-1163, 1999.

Liousse, C., Cachier, H., and Jennings, S. G.: Optical and thermal measurements of black carbon aerosol content in different environments: Variation of the specific attenuation cross-section, sigma (s), Atmos. Environ., 27A, 1203-1211, 1993.

Mader, B. T., Flagan, R. C., and Seinfeld, J. H.: Airborne measurements of atmospheric carbonaceous aerosols during ACE-Asia, J. Geophys. Res., 23, 4704, doi:10.1029/2002JD002221, 2002.

Marple, V. A., Rubow, K. L., and Behm, S. M.: A Microorifice Uniform Deposit Impactor (Moudi) - Description, Calibration, and Use, Aerosol Sci. Technol., 14, 434-446, 1991.

McMurry, P. H.: A review of atmospheric aerosol measurements, Atmos. Environ., 34, 1959-1999, 2000.

Moosmüller, H., Arnott, W. P., Rogers, C. F., Chow, J. C., Frazier, C. A., Sherman, L. E., and Dietrich, D. L.: Photoacoustic and filter measurements related to aerosol light absorption during the Northern Front Range Air Quality Study (Colorado 1996/1997), J. Geophys. Res.-Atmos., 103, 28 149-28 157, 1998.

Penner, J. E., Andreae, M. O., Annegarn, H., Barrie, L., Feichter, J., Hegg, D., Jayaraman, A., Leaitch, R., Murphy, D., Nganga, J., and Pitari, G.: Aerosols, their Direct and Indirect Effects, in: Climate Change 2001: The Scientific Basis. Contribution of Working Group I to the Third Assessment Report of the Intergovernmental Panel on Climate Change, edited by: Houghton, J. T., Ding, Y., Griggs, D. J., Noguer, M., van der Linden, P. J., Dai, X., Maskell, K., and Johnson, C. A., p. 289-348, Cambridge University Press, Cambridge, UK, and New York, NY, USA, 2001.

Petzold, A., Kopp, C., and Niessner, R.: The dependence of the specific attenuation cross section on black carbon mass fraction and particle size, Atmos. Environ., 31, 661-672, 1997.

Petzold, A., Schloesser, H., Sheridan, P. J., Arnott, W. P., Ogren, J. A., and Virkkula, A.: Evaluation of multiangle absorption 
photometry for measuring aerosol light absorption, Aerosol Sci. Technol., 39, 40-51, 2005.

Petzold, A. and Schönlinner, M.: Multi-angle absorption photometry - a new method for the measurement of aerosol light absorption and atmospheric black carbon, J. Aerosol Sci., 35, 421-441, 2004.

Raspet, R., Slaton, W. V., Arnott, W. P., and Moosmüller, H.: Evaporation-condensation effects on resonant photoacoustics of volatile aerosols, J. Atmos. Oceanic Technol., 20, 685-695, 2003.

Redemann, J., Russell, P. B., and Hamill, P.: Dependence of aerosol light absorption and single-scattering albedo on ambient relative humidity for sulfate aerosols with black carbon cores, J. Geophys. Res.-Atmos., 106, 27 485-27 495, 2001.

Reid, J. S., Hobbs, P. V., Liousse, C., Martins, J. V., Weiss, R. E., and Eck, T. F.: Comparisons of techniques for measuring shortwave absorption and black carbon content of aerosols from biomass burning in Brazil, J. Geophys. Res.-Atmos., 103, 32 031-32 040, 1998.

Rissler, J., Vestin, A., Swietlicki, E., Fisch, G., Zhou, J., Artaxo, P., and Andreae, M. O.: Size distribution and hygroscopic properties of aerosol particles from dry-season biomass burning in Amazonia, Atmos. Chem. Phys., 6, 471-491, 2006, http://www.atmos-chem-phys.net/6/471/2006/.

Rosencwaig, A.: Photoacoustics and photoacoustic spectroscopy, Wiley, New York, 1980.

Saathoff, H., Moehler, O., Schurath, U., Kamm, S., Dippel, B., and Mihelcic, D.: The AIDA soot aerosol characterisation campaign 1999, J. Aerosol Sci., 34, 1277-1296, 2003.

Schmid, H., Laskus, L., Abraham, H. J., Baltensperger, U., Lavanchy, V., Bizjak, M., Burba, P., Cachier, H., Crow, D., Chow, J., Gnauk, T., Even, A., ten Brink, H. M., Giesen, K. P., Hitzenberger, R., Hueglin, E., Maenhaut, W., Pio, C., Carvalho, A., Putaud, J. P., Toom-Sauntry, D., and Puxbaum, H.: Results of the "carbon conference" international aerosol carbon round robin test stage I, Atmos. Environ., 35, 2111-2121, 2001.
Schnaiter, M., Schmid, O., Petzold, A., Fritzsche, L., Klein, K.-F., Andreae, M. O., Helas, G., Thielmann, A., Gimmler, M., Möhler, O., Linke, C., and Schurath, U.: Measurement of wavelengthresolved light absorption by aerosols utilizing a UV-VIS extinction cell, Aerosol Sci. Technol., 39, 249-260, 2005.

Sheridan, P. J., Arnott, W. P., Ogren, J. A., Andrews, E., Atkinson, D. B., Covert, D. S., Moosmüller, H., Petzold, A., Schmid, B., Strawa, A. W., Varma, R., and Virkkula, A.: The Reno aerosol optics study: An evaluation of aerosol absorption measurement methods, Aerosol Sci. Technol., 39, 1-16, 2005.

Terhune, R. W. and Anderson, J. E.: Spectrophone measurements of the absorption of visible light by aerosols in the atmosphere, Opt. Lett., 1, 70-72, 1977.

Truex, T. J. and Anderson, J. E.: Mass monitoring of carbonaceous aerosols with a spectrophone, Atmos. Environ., 13, 507-509, 1979.

Virkkula, A., Ahlquist, N. C., Covert, D. S., Arnott, W. P., Sheridan, P. J., Quinn, P. K., and Coffman, D. J.: Modification, calibration and a field test of an instrument for measuring light absorption by particles, Aerosol Sci. Technol., 39, 68-83, 2005 a.

Virkkula, A., Ahlquist, N. C., Covert, D. S., Sheridan, P. J., Arnott, W. P., and Ogren, J. A.: A three-wavelength optical extinction cell for measuring aerosol light extinction and its application to determining light absorption coefficient, Aerosol Sci. Technol., 39, 52-67, 2005b.

Weingartner, E., Saathoff, H., Schnaiter, M., Streit, N., Bitnar, B., and Baltensperger, U.: Absorption of light by soot particles: determination of the absorption coefficient by means of aethalometers, J. Aerosol Sci., 34, 1445-1463, 2003.

Wex, H., Neususs, C., Wendisch, M., Stratmann, F., Koziar, C., Keil, A., Wiedensohler, A., and Ebert, M.: Particle scattering, backscattering, and absorption coefficients: An in situ closure and sensitivity study, J. Geophys. Res.-Atmos., 107, 8122, doi:10.1029/2000JD000234, 2002. 